\title{
EXPERIMENTAL STUDY ON SULFOALUMINATE CEMENT-BASED GROUT
}

\author{
FEI SHA*, HAIYAN LI*, ${ }^{\#}$ PENG LIU** \\ *Geotechnical and Structural Engineering Research Center, Shandong University, Jinan 250061, Shandong, China \\ **School of Civil Engineering, Central South University, 22 Shaoshan Road, Changsha 410075, China \\ \#E-mail: lop868@163.com
}

Submitted November 12, 2019; accepted January 6, 2020

\begin{abstract}
Keywords: Grouts, Sulfoaluminate cement, Fresh-state property, Mechanical performance, Microstructure
To explore some solutions for construction or repair problems, it is necessary to determine the performance of a quick-setting grout such as a sulfoaluminate cement-based grout (SACG). In this study, two typical sulfoaluminate cement (SAC) and one ordinary Portland cement $(O P C)$ were prepared, the water/solid $(W / S)$ ratio was selected as 0.6:1 - 1.2:1. The properties investigated were: the rheological behaviours, i.e., mini-slump, flowability; the fresh-state properties, i.e., effective W/S or stability, flowability losing time and initial/final setting time; the mechanical performance, i.e., flexural strength (FS), unconfined compressive strength (UCS); the mineral characteristics; microstructure and erosion resistance coefficient. The mechanical strength of blended (SAC+OPC) suspension-sodium silicate double slurries (volume ratios of 1:1 - 5:1) were determined to provide optimisation suggestions for the double slurries. The results showed that the approximate combination of an anti-washout agent and a superplasticiser should be used, the mineral composition and volume ratio were the main influence factors for the flowability losing times. The strength developments of the $S A C G$ were relatively low at high $W / S$. The strengths of the SAC double slurries are low, and a 10-30\% SAC and volume ratio of 3:1 are recommended if the SACG double slurries are applied. The sulfate erosion resistance coefficients of the SACG were much higher than 1.0 and they have obvious advantages for sulfate erosion resistance.
\end{abstract}

\section{INTRODUCTION}

In geotechnical and underground engineering, grouting technology is widely employed to strengthen the fracture, to ensure the safety of the engineering structure and to achieve the objective of effective reinforcement [1-4]. Compared with chemical grouts, cement-based grouts are inexpensive, environmentally friendly and more durable [5-7]. Owing to the relatively rapid setting, high early compressive strength, micro-expansion and good corrosion resistance [8-12], sulfoaluminate cements (SACs) are needed accordingly in the related structural or concrete engineering industries. In grouting engineering, there are relatively few studies about the performance evaluation of SAC grouting materials. To explore some solutions for construction problems, such as water plugging, rapid repair, grouting reinforcement of jointed rock, broken rock, soft soil, etc., in underground engineering, it is meaningful to evaluate and control the performance of the SAC based grout.

The hydration essence of SACG is mainly focused on the mineral hydration of the sulfoaluminate cement clinker under different additional admixtures. The following academic cement terminologies are applied herein: $\mathrm{C}=\mathrm{CaO}, \mathrm{S}=\mathrm{SiO}_{2}, \overline{\mathrm{S}}=\mathrm{SO}_{3}, \mathrm{~F}=\mathrm{Fe}_{2} \mathrm{O}_{3}$, and $\mathrm{H}=\mathrm{H}_{2} \mathrm{O}$ [13]. The main mineral components of SAC are $\mathrm{C}_{4} \mathrm{~A}_{3} \overline{\mathrm{S}}$, $\beta-\mathrm{C}_{2} \mathrm{~S}, \mathrm{C}_{4} \mathrm{AF}, \mathrm{C}_{2} \mathrm{~A} \overline{\mathrm{S}}, \mathrm{C}_{3} \mathrm{~A}$ and $\mathrm{C} \overline{\mathrm{S}}$ or $\mathrm{C} \overline{\mathrm{S}} \mathrm{H}_{2}$, etc. The hydration products of ordinary SAC are different from those of OPC. In the initial period, the $\mathrm{C}_{4} \mathrm{~A}_{3} \overline{\mathrm{S}}$ hydrates to form AFt (ettringite) in the absence of $\mathrm{CS}$ or $\mathrm{CS} \mathrm{H}_{2}(1)$. The continuous hydration of $\mathrm{C}_{2} \mathrm{~S}$ can provide the strength development in the later period, and the $\mathrm{CH}$ generated (2) can promote the formation of AFt (4-5). If there is not enough $\mathrm{C} \overline{\mathrm{S}}$ or $\mathrm{C} \overline{\mathrm{S}} \mathrm{H}_{2}$, the chemical reactions of (5) and (6) easily take place. The primary hydration products of the calcium sulfoaluminate cement (CSA) are approximately $\mathrm{AFt}, \mathrm{AFm}, \mathrm{AH}_{3}$. At the same time, C-S-H (I), $\mathrm{C}_{2} \mathrm{~A} \overline{\mathrm{S}} \mathrm{H}_{8}$, $\mathrm{C}_{4}(\mathrm{~A}, \mathrm{~F}) \mathrm{X}_{2} \cdot y \mathrm{H}_{2} \mathrm{O}$ and $\mathrm{C}_{3} \mathrm{AH}_{6}$ can be formed in hydration process $[14,15]$.

$$
\begin{gathered}
\mathrm{C}_{4} \mathrm{~A}_{3} \overline{\mathrm{S}}+2 \mathrm{C} \overline{\mathrm{S}} \mathrm{H}_{2}+34 \mathrm{H} \rightarrow \mathrm{C}_{6} \mathrm{AS}_{3} \mathrm{H}_{32}+2 \mathrm{AH}_{3} \\
\mathrm{C}_{2} \mathrm{~S}+2 \mathrm{H} \rightarrow \mathrm{CH}+\mathrm{C}-\mathrm{S}-\mathrm{H}(\mathrm{I}) \\
\mathrm{C}_{4} \mathrm{~A}_{3} \overline{\mathrm{S}}+8 \mathrm{C} \overline{\mathrm{S}} \mathrm{H}_{2}+6 \mathrm{CH}+74 \mathrm{H} \rightarrow 3 \mathrm{C}_{6} \mathrm{AS}_{3} \mathrm{H}_{32} \\
\mathrm{AH}_{3}+3 \mathrm{CH}+3 \mathrm{C} \overline{\mathrm{S}} \mathrm{H}_{2}+20 \mathrm{H} \rightarrow 3 \mathrm{C}_{6} \mathrm{~A}_{3} \mathrm{H}_{32} \\
\mathrm{C}_{4} \mathrm{~A}_{3} \overline{\mathrm{S}}+18 \mathrm{H} \rightarrow \mathrm{C}_{4} \mathrm{~A} \overline{\mathrm{S}} \mathrm{H}_{12}+2 \mathrm{AH}_{3} \\
3 \mathrm{C}_{6} \mathrm{~A}_{\bar{S}_{3}} \mathrm{H}_{32} \rightarrow \mathrm{C}_{4} \mathrm{~A} \overline{\mathrm{S}} \mathrm{H}_{12}+2 \mathrm{C} \overline{\mathrm{S}} \mathrm{H}_{2}+16 \mathrm{H}
\end{gathered}
$$

The property of SAC at a low water/solid (W/S) ratio and the property of Portland cement-based grouts have been studied by many researchers [16-19], however, the mechanism, property and workability of SACG at higher W/S $(\geq 0.8)$ ratios are not reported systematically [20-22]. To determine and improve the performance of a quick-setting grout such as SACG, it is necessary 
and urgent to study and improve the performance of the SACG through laboratory tests. In this study, two typical SAC and one ordinary Portland cement (OPC) slurries (0.6:1 - 1.2:1) were prepared, and a superplasticiser (SP) and an anti-washout agent (AWA) were combined to improve the fluidity and stability. Based on the requirements of the grouting practice, the rheological behaviours, i.e., mini-slump, flowability; the fresh-state properties, i.e., effective $\mathrm{W} / \mathrm{S}$ or stability, flowability losing time and initial/final setting time; the mechanical performance, i.e., flexural strength (FS), unconfined compressive strength (UCS); the mineral characteristic; microstructure and erosion resistance coefficient were investigated. Meanwhile, the effects of various factors (cement type, volume ratio, W/S, curing day, etc.) were analysed. The mechanical strength of the blended (SAC+OPC) suspension-sodium silicate double slurries (the volume ratios of $1: 1-5: 1$ ) were determined.

\section{Significance}

Many researchers have presented the performance of SAC especially at a lower $\mathrm{W} / \mathrm{S}$ ratio $(<0.8)$, and cement-based grouts with a high $\mathrm{W} / \mathrm{S}$ ratio $(\geq 0.8)$ have been applied in grouting engineering. However, scientific findings about the synergistic effects of the mineral composition of the SAC, high W/S, SP and AWA on the workability, determination of the mechanical strength and erosion resistance of the SACG, compatibility of the SAC and water glass in the SACG double slurries, and optimisation suggestion of the SACG are lacking. Therefore, it is urgent and essential to ensure the quality of the SACG suspensions and provide key property data that are reproducible in the field. This experimental study was designed to fill this gap. The purposes of this experimental study were as follows:

- To study the combined effects of the mineral composition of the SAC, high W/S, SP and AWA on the workability of the SACG single slurries, which is deficient in current research studies;

- To evaluate the rheological behaviour (mini-slump and flowability) and the fresh-state properties (effective $\mathrm{W} / \mathrm{S}$ or stability, flowability losing time and initial/ final setting time) of the SACG slurries;
- To determine the main mechanical strength (flexural strength (FS) and unconfined compressive strength (UCS)), the mineral characteristic (XRD), the microstructures (SEM and MIP) and erosion resistance of the SACG stone bodies, therefore, providing the missing key data in the related references;

- To evaluate the compatibility of the SAC blended (SAC+OPC) materials and water glass comparatively, thus, providing elementary suggestions for formulation optimisations of SACGs in practical engineering applications.

\section{EXPERIMENTAL}

Raw materials

Considering multiple factors such as practicability, typicality, performance, cost, etc., the CEM II/B-M Type Portland-based cement (OPC) 42.5R from Jinan was selected [23]. The two 42.5R SACs were selected from Jining (SAC1) of Shandong province and Tangshan (SAC2) of Hebei province, respectively. The sodium silicate solution was selected from a company in Jinan, its Baume degree and module are 40 and 3.0, respectively. The chemical compositions and raw materials of the above cements are shown in Table 1. Table 2 shows the property of the naphthalene-based SP (hereinafter called N) in this study. To improve the fluidity and stability of the fresh grouts, a polynaphthalene based SP and a polysaccharide-based AWA were used. All the grouts were prepared with potable water [24, 25].

The particle size distributions (PSD) of SAC1, SAC2 and OPC were measured through a laser diffraction technique based on ISO 13320-1 [26]. The PSD characteristic assists in better understanding the performance of the cementitious suspensions. Figure 1 present the PSD feature (cumulative percentage passing and percentage passing) of the grouts (SAC1, SAC2 and OPC). The average particle sizes $\left(D_{50}\right)$ of SAC1, SAC2 and OPC were approximately 6.10, 6.98 and $10.65 \mu \mathrm{m}$, respectively. The $D_{90}$ particle sizes of SAC1, SAC2 and OPC were about 26.82, 36.53 and $32.24 \mu \mathrm{m}$, respectively. At the particle size ranges of $1.0-20 \mu \mathrm{m}$, the cumulative

Table 1. The main chemical composition of SAC1, SAC2 and OPC (wt. \%).

\begin{tabular}{lcccccccccc}
\hline Materials & $\mathrm{CaO}$ & $\mathrm{SiO}_{2}$ & $\mathrm{Al}_{2} \mathrm{O}_{3}$ & $\mathrm{Fe}_{2} \mathrm{O}_{3}$ & $\mathrm{MgO}$ & $\mathrm{Na}_{2} \mathrm{O}$ & $\mathrm{K}_{2} \mathrm{O}$ & $\mathrm{TiO}_{2}$ & $\mathrm{SO}_{3}$ & $\mathrm{LOI}$ \\
\hline $\mathrm{SAC} 1$ & 46.12 & 9.07 & 26.86 & 2.63 & 0.56 & 0.31 & 0.53 & 0.46 & 11.85 & 0.96 \\
$\mathrm{SAC} 2$ & 46.16 & 8.03 & 27.87 & 2.36 & 1.11 & 0.29 & 0.42 & 0.39 & 11.57 & 1.17 \\
OPC (CEM II/B-M) & 54.06 & 21.65 & 9.15 & 2.85 & 3.90 & 0.24 & 0.66 & 0.49 & 3.62 & 2.87 \\
\hline
\end{tabular}

Table 2. The properties of the naphthalene-based SP used in this study.

\begin{tabular}{cccccccc}
\hline Symbol & Type & Aspect & $\begin{array}{c}\text { Bulk density } \\
\left(\mathrm{g} \cdot \mathrm{ml}^{-1}\right)\end{array}$ & $\begin{array}{c}\text { Solid content } \\
(\%)\end{array}$ & $\mathrm{pH}$ & $\begin{array}{c}\text { Chloride ion } \\
\text { content }\end{array}$ & \multicolumn{2}{c}{ Repulsion mechanism } \\
\hline $\mathrm{N}$ & FDN-C & Dark brown & 1.2 & $\geq 92$ & $7-9$ & Chloctrostatic & Steric hindrance \\
\hline
\end{tabular}


percentage passing of SAC1 or SAC2 was higher than that of the OPC, and that of the SAC1 was the highest. The amounts of fine particles with sizes of $1-10 \mu \mathrm{m}$ were higher than those of the OPC, it indicated the PSD characteristic of the SAC had obvious advantages compared with those of the OPC. The PSD difference between SAC1 and SAC2 was small.

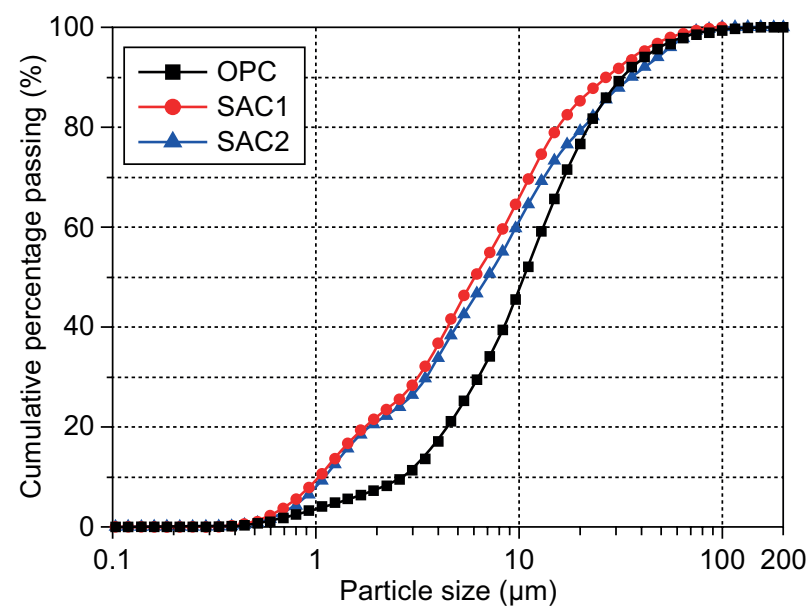

Figure 1. The particle size distributions (PSD) of the SAC1, SAC2 and OPC.

Preparation of single and double slurries

Initially, all the raw materials for this study were stored at $25^{\circ} \mathrm{C}$, then the cements were mixed uniformly with the required water and the fresh slurry was agitated automatically at $240 \mathrm{rpm}$ for 10 minutes. The W/S ratios were chosen as $0.6,0.8,1.0$ and 1.2 by weight. For the fresh slurries with the AWA by itself and in combination with the SP, the AWA (relative to the weight of the water) or the SP (relative to the weight of the solids) was firstly added to the needed water. The AWA can improve the stability and retention rate under a waterrich environment or a relatively high flow speed of water, and this is helpful for water plugging and reinforcement during the construction or operation of underground engineering. However, the AWA content ought not to be so excessive as to guarantee enough spreading ability or the flowability of the slurries. Therefore, the combination of the AWA and SP can provide a balance

Table 3. The key values of the particle size distribution of the SAC1, SAC2 and OPC in this study.

\begin{tabular}{lcccccc}
\hline $\begin{array}{l}\text { Cement } \\
\text { type }\end{array}$ & $\begin{array}{c}\mathrm{D}_{10} \\
(\mu \mathrm{m})\end{array}$ & $\begin{array}{c}\mathrm{D}_{50} \\
(\mu \mathrm{m})\end{array}$ & $\begin{array}{c}\mathrm{D}_{80} \\
(\mu \mathrm{m})\end{array}$ & $\begin{array}{c}\mathrm{D}_{85} \\
(\mu \mathrm{m})\end{array}$ & $\begin{array}{c}\mathrm{D}_{90} \\
(\mu \mathrm{m})\end{array}$ & $\begin{array}{c}\mathrm{D}_{95} \\
(\mu \mathrm{m})\end{array}$ \\
\hline SAC1 & 1.039 & 6.079 & 15.601 & 19.708 & 26.828 & 40.616 \\
SAC2 & 1.115 & 7.019 & 20.861 & 16.225 & 35.824 & 52.414 \\
OPC & 2.686 & 10.636 & 22.066 & 25.972 & 32.268 & 45.553 \\
\hline
\end{tabular}

of the above contradictory performance. Considering the ordinary particle size distribution (PSD), the quick setting characteristics of the SAC and the results of the preliminary experiments, the AWA and SP contents were selected as $0.03 \%$ and $0.7 \%$ at lower $\mathrm{W} / \mathrm{S}$ ratios $(0.6$ to 0.8 ), and $0.12 \%$ AWA and $0.5 \%$ SP were used at higher $\mathrm{W} / \mathrm{S}$ ratios $(0.8-1.2)$. The single slurries were prepared without, with AWA, and AWA+SP. For dynamic water or water gushing with high pressure, the cementitious suspension-water glass should be applied to block or resist. As for the preparation of the double slurries, the cement-based single slurry was placed in a specific container immediately after its preparation, the water glass single slurry was poured into the cement-based single slurry, and quick mixing was applied during the very quick hardening process.

\section{Experimental approaches}

The ambient temperatures of all the measurements were $25{ }^{\circ} \mathrm{C}$. To characterise the spreading ability and flowability of the fresh SACG slurries, the mini-slump spreading diameter and Marsh cone flow time were measured and combined systematically. These tests are easy ways to evaluate and control the rheological behaviour of the fresh slurries prepared at worksites. The mini-slump measurement can be calculated as the average spreading diameter in a plate, the mini-slump cone is similar to that used for determining concrete consistency based on ASTM C-143 [27]. In addition, the $\Phi_{\text {bottom }}, \Phi_{\text {top }}$ and $h$ (height) of the slump cone were 60, 36 and $60 \mathrm{~mm}$, respectively [28]. The elapsed time of the specific volume of the fresh suspension through the Marsh cone can be defined as the Marsh cone flow time based on ASTM C 939 [29] (ASTM, 2010). It is one part of the family of orifice measurements or the ORIMET [30] (Ozawa et al., 1995). Firstly, $1500 \mathrm{ml}$ of fresh grout was filled in a Marsh cone after its preparation process, the elapsed time of $946 \mathrm{ml}$ fresh grout was recorded as $F($ s), and the internal orifice diameter of the Marsh cone is $4.8 \mathrm{~mm}$. In comparison, the flow time of $946 \mathrm{ml}$ of water was about $26 \pm 0.5 \mathrm{~s}$.

The bleeding rate is measured as the ratio of $\Delta V / V_{0}$ three hours later, the $V_{0}$ and $\Delta V$ are the initial volume and volume of the bleeding water, respectively. According to the bleeding rates, the effective $\mathrm{W} / \mathrm{S}$ ratio was calculated as follows:

$$
\text { Effective } \mathrm{W} / \mathrm{S}=\left(1-C_{B}\right) \times \text { Initial W/S }
$$

where $C_{B}$ is the coefficient of the bleeding volume. The fresh suspension is regarded as "stable" if its bleed capacity was not over $5 \%$ [31-33]. A Vicat needle apparatus was used to determine the initial and final setting time of the SACGs. Based on ASTM Standard C191 [34], the initial setting time was recorded when the penetration height of the Vicat needle was $25 \mathrm{~mm}$, and the final setting time was determined when the needle 
did not leave a complete circular impression on the grout surface or the penetration height of the needle was less than $0.5 \mathrm{~mm}$. In this study, the flowability losing time was determined by the "pouring cup method". The cementbased single slurry and single slurry of the water glass were placed in two paper cups separately. The water glass was poured into the cup equipped with the cementbased suspension firstly, and the newly formed double slurries were poured between the two cups persistently till the flowability or the fluidity of the double slurry was totally lost [5]. Based on the requirements of the grouting practice and pumping capacity of the grouting pump, the volume ratios of the cement suspension and sodium silicate were chosen as 1:1, 2:1, 3:1 and 5:1.

The FSs were determined to give practical references for such SACGs. The size of the cubic specimen mould was $40 \times 40 \times 160 \mathrm{~mm}$, Vaseline was used to seal the possible gap at the bottom side wall position of the cubic mould. Based on ASTM C78-16 [35] and GB/T 17671 [36], the 3-day and 28-day FS tests of the hardened grouts were conducted, and the loading rate is $2 \mathrm{~mm} / \mathrm{min}$. Although it is known that the values of the UCSs are higher than those of the FSs for cement-based materials, the specific UCSs of such SACGs ought to be provided specifically for the grouting practices. According to GB/T 17671 [37], ASTM C942-15 [36] and ASTM C39/C39M-16 [38] (ASTM, 2016), the loading rate for the compression test was $2 \mathrm{kN} \cdot \mathrm{s}^{-1}$ and the dimension of the specimen was $40 \times 40 \times 160 \mathrm{~mm}$. The specimens were cured in a moist chamber at $25 \pm 3{ }^{\circ} \mathrm{C}$ and $100 \%$ RH (relative humidity) for the different curing times. The failure characteristics of the fracture surface were recorded and compared. The grout stone bodies (SAC1, $\mathrm{SAC} 2$ and $\mathrm{OPC}$ ) were cured in pure water, sodium sulfate solutions and sodium chloride solutions, respectively. The concentrations of the sulfate ion and chloride ion were all $10 \%$ in this study. The erosion time of the grout stone bodies was 120 days. Based on GB/T 749 [39] and ASTM C580-18 [40], the erosion resistance coefficient

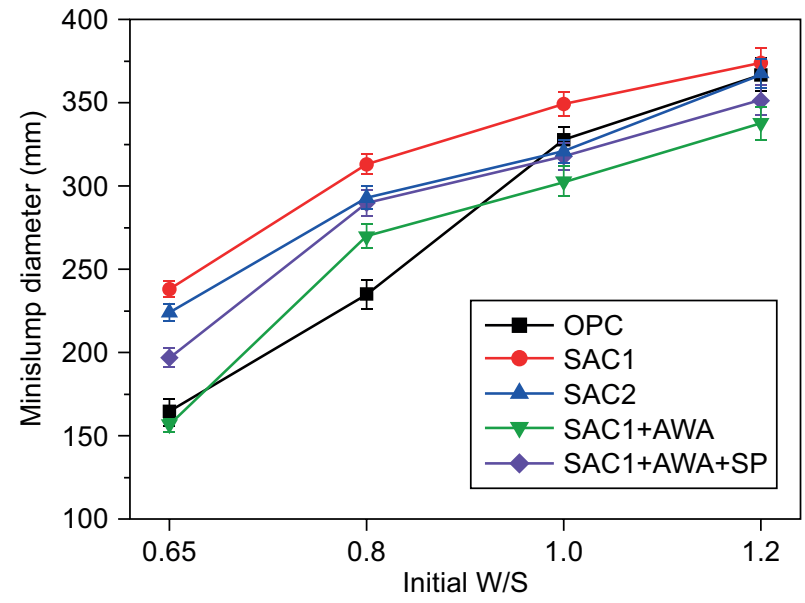

Figure 2. The mini-slump (mm) of the SAC1, SAC2 and OPC suspensions at a W/S of $0.6: 1-1.2: 1$.
$(K)$ was used to evaluate the anti-erosion ability, and $K$ was calculated as the 180-day flexural strength ratios of the grouts cured in the erosion solutions and those cured in water.

In this study, a D8 ADVANCE type X-ray diffraction analyser was applied to obtain the hydration minerals, the scanning angle and the scanning speed were $5-60^{\circ}$ and 4 - 5 degrees $\cdot \mathrm{min}^{-1}$, respectively. The microstructure of the grout was studied by using a scanning electron microscope (SEM). Small broken pieces of hardened SACGs were kept in absolute ethyl alcohol for the SEM measurements.

\section{RESULTS AND DISCUSSION}

Spreading ability and flowability

The spreading ability and flowability of the fresh SACG suspensions were represented by the flow time (s) and mini-slump (mm), respectively. The result of the mini-slump is shown in Figure 2.

In Figure 2, the effects of the W/S on the mini-slump were relatively more significant compared with those of the cement type, for example, the mini-slump ranges of the SAC1, SAC2 and OPC suspensions were about 313-349, 293-321 and 201-328 mm, respectively. At the W/S of 1.0-1.2, the mini-slump ranges of the SAC1, SAC2 and OPC suspensions were about 349-374, 321-368 and 328-367 mm, respectively. Meanwhile, the decreasing effects caused by the AWA on the mini-slumps were also obvious especially for the low W/Ss. At W/Ss of 0.65 to 0.8 and 1.0 to 1.2 , the mini-slumps of the SAC1 grout with the AWA ranged from 157 to 270 and 303 to $338 \mathrm{~mm}$, respectively. The adverse effect of the AWA can be offset with the different degrees through the combination of the SP and AWA. For example, compared with the mini-slumps of the SACG with the AWA only, the rate of increase of those with the AWA+SP ranged from $7.4-25.5 \%$ and from $4.1-5.0 \%$ when the W/S were

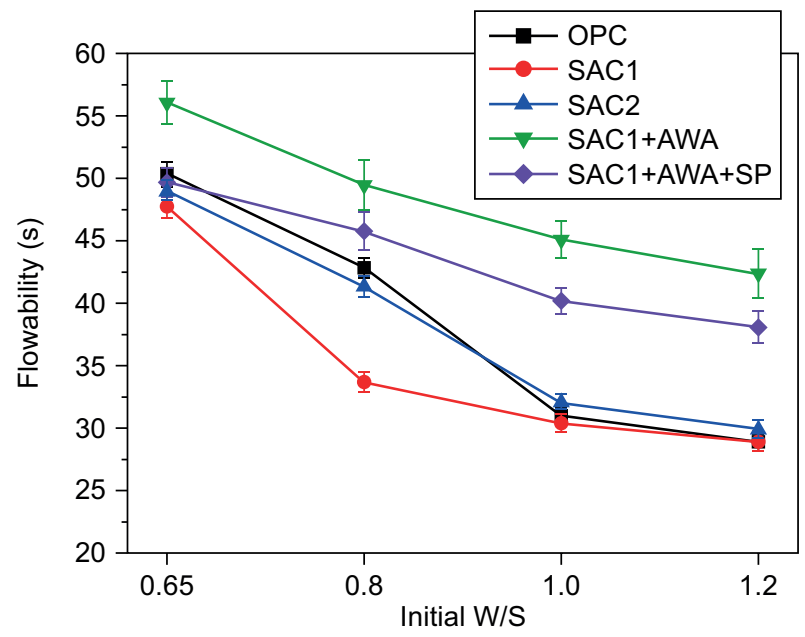

Figure 3. The mini-slump (mm) of the SAC1, SAC2 and OPC suspensions at a W/S of $0.6: 1-1.2: 1$. 
$0.65-0.8$ and $1.0-1.2$, respectively. It was also observed that the mini-slumps of the SACG were slightly higher than those of the OPC grouts, this might be due to the unique chemical and mineral composition when the key PSD values were almost similar. The mini-slumps tended to be similar especially as the W/S increased, this might be because that the slurries are likely more susceptible to the friction or resistance under the relatively low shear rates.

As presented in Figure 3, the W/S and the AWA were the main influence factors for the flowability of the fresh slurries. The effects of the W/S on the flowability were remarkable especially when the W/S reached or exceeded 1.0. For example, at a W/S of $0.65-0.8,0.8-1.0$ and 1.0 - 1.2, the flowabilities of the SACG (SAC1) were about 47.8 - 33.7, $33.7-30.4$ and $30.4-29.0$, respectively. The increase in the effect of the flowability was also obvious even at higher $\mathrm{W} / \mathrm{Ss}$ of $1.0-1.2$, and the combination of AWA and SP can be helpful for improving this adverse phenomenon. For example, compared with the flowability of the SACG with the AWA only, the decreasing rate of the SACG (SAC1) with the AWA+SP ranged from $3.7-6.45 \%$ and from $4.3-4.9 \%$ when the W/Ss were $0.65-0.8$ and $1.0-1.2$, respectively. The decrease in the rate was not so high, this might be because that the variation of the flow time was sensitive when the slurries are subjected to a high shear rate in the Marsh cone flow tests. Meanwhile, it was observed that the difference between the SAC and OPC was not generally obvious. The influence of the chemical composition (cement type) on the flowability or spreading ability of the fresh slurry was relatively obvious at lower $\mathrm{W} / \mathrm{Ss}(0.65-0.8$ or $0.65-1.0)$

\section{Effective W/S of single slurries}

The effective W/S was introduced to analyse the stability and effective reaction of the SAC and the OPC suspensions. It is worth mentioning here that the effective $\mathrm{W} / \mathrm{S}$ is necessary and helpful for understanding

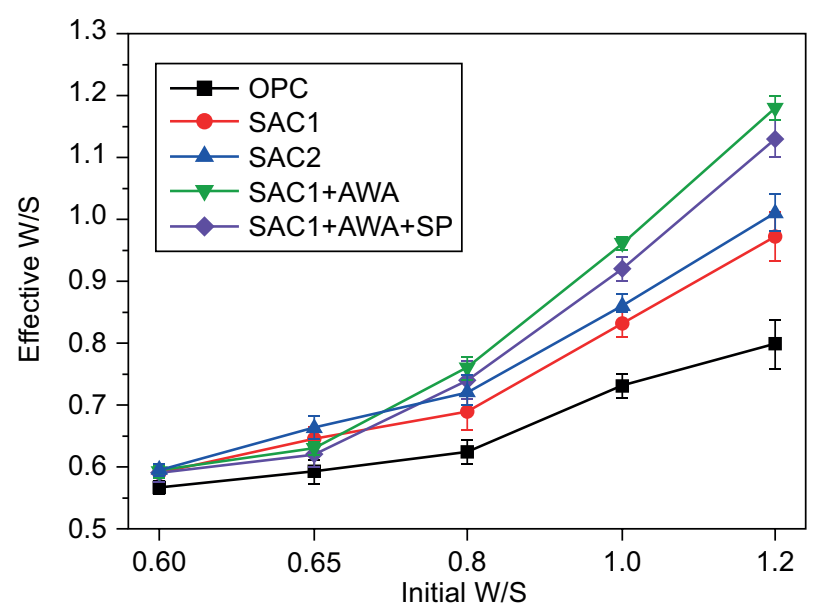

Figure 4. The effective W/S of the fresh SAC1, SAC2 and OPC suspensions at a W/S of $0.6-1.2$. the real mechanical properties of the hardened MCGs, considering the bleeding effect. The result of the effective W/S for the different initial W/S is shown in Figure 4.

As presented in Figure 4, the difference between the effective $\mathrm{W} / \mathrm{S}$ and the initial W/S became larger when the initial W/S became larger without the AWA. For example, the effective W/Ss of SAC1, SAC2 and OPC were $0.83-0.97,0.86-1.01$ and $0.73-0.80$, respectively, at the initial W/S range of $1.0-1.2$. For SAC1, SAC2 and $\mathrm{OPC}$, the bleeding capacity started to exceed $5 \%$ when the initial $\mathrm{W} / \mathrm{S}$ ratio was larger than $0.6,0.7$ and 0.8 gradually. The effective $\mathrm{W} / \mathrm{S}$ of the SACG was generally higher than that of the OPC grout, this might be because that the unique minerals such as the CSA were more helpful for improving the stability of the fresh slurries. The difference between SAC1 and SAC2 was small without the SP. Stable fresh suspensions are recommended, while suspensions with a lower effective $\mathrm{W} / \mathrm{S}$ are inclined to provide only a partial filling of the strata voids because of their higher bleeding volume [41]. With the addition of the AWA, the effective W/Ss were almost the same as the initial W/Ss, regardless of the values of the initial W/S. The combination effects of the AWA and SP on the effective W/S were acceptable and practical.

\section{Setting time and flowability losing time}

The setting time is of major importance to grouting engineering, because too short a time can damage the equipment and too long a time can delay the execution of the work and reduce the grouting efficiency [6]). The initial/final setting time and flowability losing time were necessary to comprehensively evaluate the workability of the single and double slurries (SAC1, SAC2 and OPC). Table 4 presents the initial/final setting times of the single slurries (a W/S of $0.6-1.2$ ) of the fresh cementitious single slurries.

Determination of the initial/final setting time is practical for operations involving repairs, the practical final setting times were evaluated because the subsequent drilling must wait for the final setting of the grout in the previous grouting holes. As shown in Table 4, the initial/ final setting times obviously increased with an increase in the W/S. Compared with the OPC single slurry, the

Table 4. The initial and final setting times of the SAC1, SAC2 and OPC single slurries (W/S of 0.6:1 - 1.2:1).

\begin{tabular}{lcccc}
\hline Type & $0.6(\mathrm{~h})$ & $0.8(\mathrm{~h})$ & $1.0(\mathrm{~h})$ & $1.2(\mathrm{~h})$ \\
\hline SAC1, Initial & 0.90 & 1.23 & 1.40 & 1.78 \\
SAC2, Initial & 0.87 & 1.19 & 1.70 & 1.97 \\
OPC, Initial & 6.51 & 6.92 & 7.22 & 7.92 \\
SAC1, Final & 1.10 & 1.40 & 1.57 & 2.08 \\
SAC2, Final & 1.15 & 1.37 & 2.25 & 2.38 \\
OPC, Final & 8.60 & 8.90 & 9.50 & 10.60 \\
\hline
\end{tabular}


unique mineral composition and hydration mechanism of the SACG determined its short initial and final setting times. For example, at the W/S of $0.8-1.2$, the initial/ final setting times of the SAC1, SAC2 and OPC were $1.23-1.78 / 1.40-2.08 \mathrm{~h}, 1.19-1.97 / 1.37-2.38 \mathrm{~h}$ and 6.92 - 7.92/8.90 - $10.60 \mathrm{~h}$, respectively. The difference between the initial and final setting times was small for the SAC1 or SAC2 grouts at each W/S. Meanwhile, the initial or final setting time of SAC1 was very close to that of SAC2. The quick-setting characteristic of the SACG was more suitable for rapid water blocking and reinforcement in unique repair practices. Table 5 shows the flowability losing time of the fresh cementitious suspension-water glass double slurries.

It should be noted that the spreading ability of the double slurries was affected by the flowability losing time, which was calculated from the mixing moment of the cementitious single slurry and the water glass slurry. In Table 5, the flowability losing times of the double slurries generally decreased with an increase in the volume ratio $(1: 1-5: 1)$ and a decrease in the $\mathrm{W} / \mathrm{S}$. Although there was some randomness for SAC1

Table 5. The flowability losing time of the SAC1, SAC2 and OPC double slurries (VC:VS $=1: 1,2: 1,3: 1$ and $5: 1, \mathrm{~W} / \mathrm{S}$ of $0.8,1.0$ and 1.2).

\begin{tabular}{lrrrr}
\hline \multirow{2}{*}{ Type } & \multicolumn{4}{c}{ VC:VS } \\
\cline { 2 - 5 } & $1: 1(\mathrm{~s})$ & $2: 1(\mathrm{~s})$ & $3: 1(\mathrm{~s})$ & $5: 1(\mathrm{~s})$ \\
\hline SAC1, 0.8 & 205.36 & 92.00 & 45.19 & 23.32 \\
SAC2, 0.8 & 203.21 & 89.02 & 44.21 & 22.87 \\
OPC, 0.8 & 35.75 & 18.30 & 14.43 & 9.05 \\
SAC1, 1.0 & 251.21 & 119.88 & 114.87 & 40.88 \\
SAC2, 1.0 & 250.32 & 118.45 & 112.28 & 39.97 \\
OPC, 1.0 & 32.57 & 22.55 & 14.68 & 9.97 \\
SAC1, 1.2 & 338.84 & 159.56 & 114.15 & 19.43 \\
SAC2, 1.2 & 321.64 & 152.39 & 112.01 & 18.89 \\
OPC, 1.2 & 44.22 & 24.80 & 17.03 & 12.31 \\
\hline
\end{tabular}

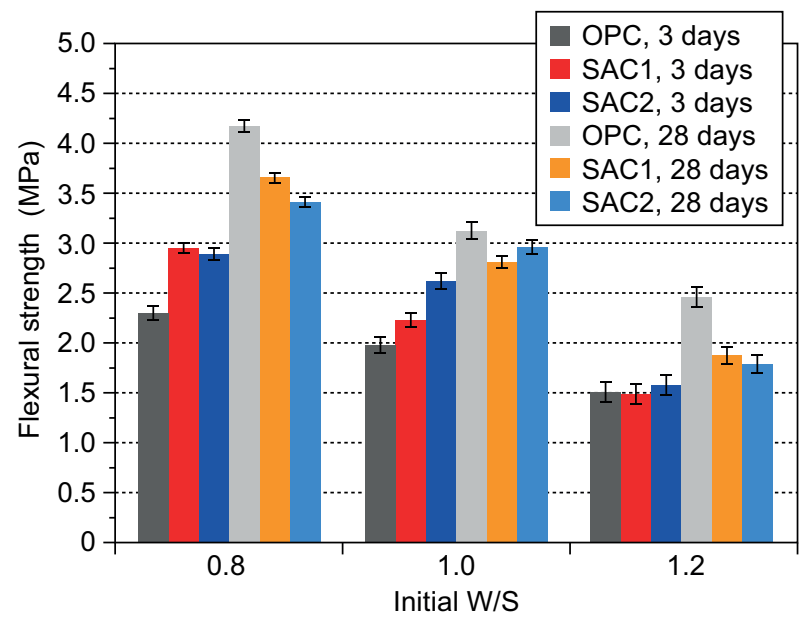

a) 3 days and SAC2, the chemical composition (cement type) and volume ratio were the main factors influencing the flowability losing times of the OPC double slurries. It was observed that the flowability losing times of the OPC double slurries (less than $60 \mathrm{~s}$ ) were much less than those of the SAC double slurries. It could be concluded that the gelling reaction of the SAC suspension-sodium silicate was not so effective or violent. The short flowability losing time of the double slurry can guarantee the fast or timely plugging of dynamic water derived from water gushing in underground engineering.

\section{FS and UCS of the grout stone body}

Figure $5 \mathrm{a}$ and $\mathrm{b}$ show the FSs and UCSs (3d and 28d) of the single slurry stone bodies. The initial W/Ss were $0.8,1.0$ and 1.2.

In Figure 5a, the 3-day FSs of the SAC1, SAC2 and OPC single slurry stone bodies were approximately $2.95-2.23,2.89-2.62$ and $2.30-1.98 \mathrm{MPa}$ at the initial $\mathrm{W} / \mathrm{S}$ of $0.8-1.0$, respectively. The FSs of the SAC suspensions were generally higher than those of the OPC single slurries at the early age (3-day), the related differences are not obvious probably because of the high W/S, the brittleness characteristic, bleeding, etc. However, the 28-day FSs of the OPC single slurry stone bodies $(4.17-2.46 \mathrm{MPa})$ were generally higher than those of SAC1 (3.66 - 1.87 MPa) and SAC2 (3.41 - 1.79 MPa) at the initial W/S of $0.8-1.2$. It could be attributed to that the FS developments of the SAC are lower than those of the OPC at W/S of $0.8-1.2$, and the stone bodies of the 42.5R type OPC single slurries matured well in the curing age of 28-days. The FS differences between SAC1 and SAC2 were small, although some randomness at the different W/Ss existed. As shown in Figure $5 \mathrm{~b}$, the 3-day UCSs of the SAC1, SAC2 and OPC single slurry stone bodies were approximately $6.97-12.76,6.04-12.28$

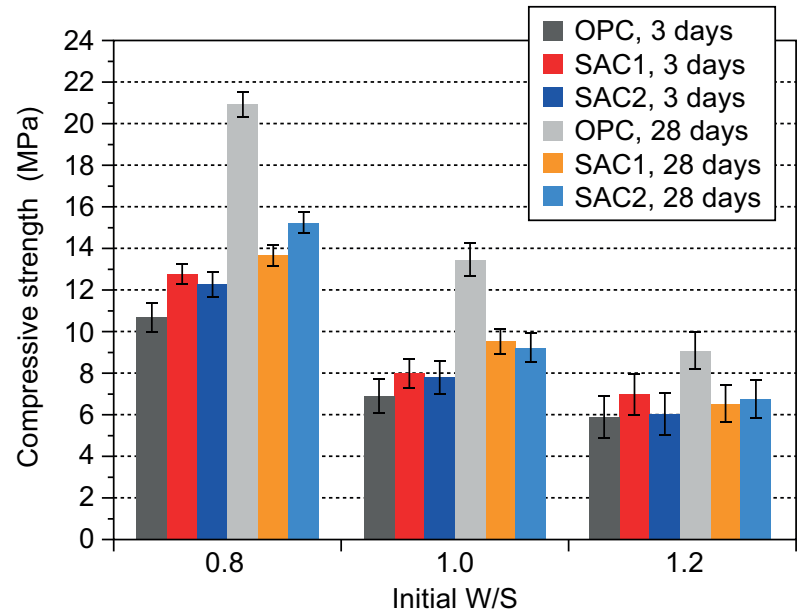

b) 28 days

Figure 5. The FSs and UCSs ( $3 \mathrm{~d}$ and $28 \mathrm{~d}$ ) of the single slurry stone. 
and $5.87-10.68 \mathrm{MPa}$ at the W/S of $0.8-1.0$, respectively. The UCSs of the SAC single slurry stone bodies were obviously higher than those of the OPC at the early age (3-day). While the 28-day UCSs of the OPC single slurry stone bodies $(20.91-9.07 \mathrm{MPa})$ were generally higher than those of SAC1 (13.66 - 6.52 MPa) and SAC2 $(15.24-6.74 \mathrm{MPa})$ at a W/S of $0.8-1.2$. It could be attri-buted to that the $42.5 \mathrm{R}$ type OPC single slurry stone bodies matured well, and the UCS developments of the $\mathrm{SAC}$ are lower than those of the OPC from 3-days to 28 -days at a W/S of $0.8-1.2$. It is well known that the cementitious material is brittle, and its flexural or shear strength is low compared with its compressive strength. The determined FS values help to provide a significant reference for such SACGs in grouting practices.

Figure 6 presents the fracture surface photos of the single slurries, and the W/Ss were 1.0 and 1.2.

In Figures $6 \mathrm{a}-\mathrm{c}$, at a W/S of 1.0, there were obvious differences in the colour and sedimentation between the SAC and OPC single slurry stone bodies. For example, the colour of the SACG stone body was brown with different shades, while the general colour of the OPC was grey. At a W/S of 1.0, the height of the SACG was almost the same as its width, and the height of the OPC was less than the related width. This indicated that the bleeding of the SACG was small and the SACG was more stable, and it was in accordance with the results

of the higher effective W/S of the SACG in Figure 4. In Figures $6 \mathrm{~d}-\mathrm{f}$, at a W/S of 1.2 , there were also obvious differences in the colour and sedimentation between the SAC and OPC single slurry stone bodies. At a W/S of 1.2 , the height of the OPC single slurry stone body was markedly less than its width, and the height of the SACG was close to its width. This indicated that the SACG was more stable with a higher effective W/S. Meanwhile, the sedimentation and fracture uniformity of the SACG

Table 6. The FS and UCS of the SAC1, SAC2 and OPC double slurries (VC:VS $=1: 1,2: 1,3: 1$ and $5: 1$, initial W/S of 1.0).

\begin{tabular}{lrccc}
\hline \multirow{2}{*}{ Type } & \multicolumn{4}{c}{ VC:VS } \\
\cline { 2 - 5 } & $1: 1(\mathrm{~s})$ & $2: 1(\mathrm{~s})$ & $3: 1(\mathrm{~s})$ & $5: 1(\mathrm{~s})$ \\
\hline $3 \mathrm{~d}$, OPC, FS & 0.40 & 1.14 & 0.76 & 0.86 \\
3 d, SAC1, FS & 0.36 & 0.19 & 0.21 & 0.39 \\
3 d, SAC2, FS & 0.41 & 0.20 & 0.21 & 0.28 \\
28 d, OPC, FS & 1.27 & 1.42 & 1.44 & 1.94 \\
28 d, SAC1, FS & 0.61 & 0.35 & 0.36 & 0.59 \\
28 d, SAC2, FS & 1.15 & 0.34 & 0.32 & 0.30 \\
3 d, OPC, UCS & 1.30 & 17.64 & 14.56 & 10.97 \\
3 d, SAC1, UCS & 1.88 & 1.27 & 0.75 & 3.03 \\
3 d, SAC2, UCS & 1.55 & 0.71 & 0.73 & 0.97 \\
28 d, OPC, UCS & 10.85 & 19.30 & 22.31 & 18.01 \\
28 d, SAC1, UCS & 2.49 & 1.82 & 1.70 & 1.76 \\
28 d, SAC2, UCS & 3.85 & 1.70 & 0.92 & 1.33 \\
\hline
\end{tabular}

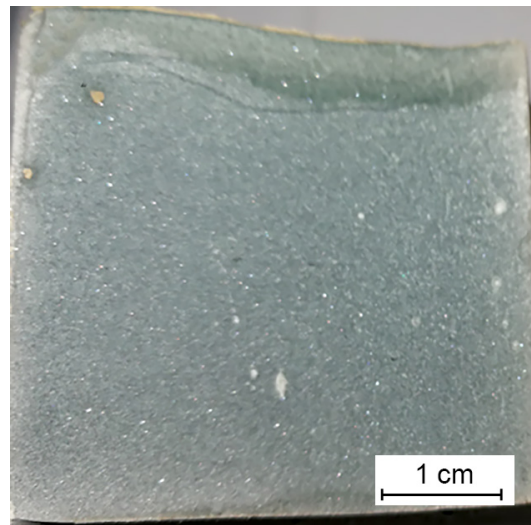

a)

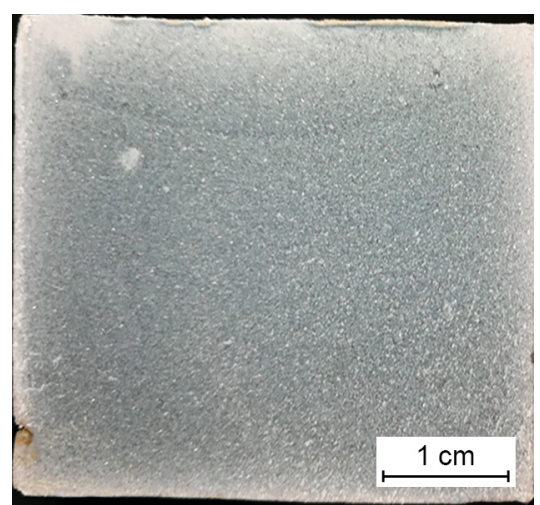

d)

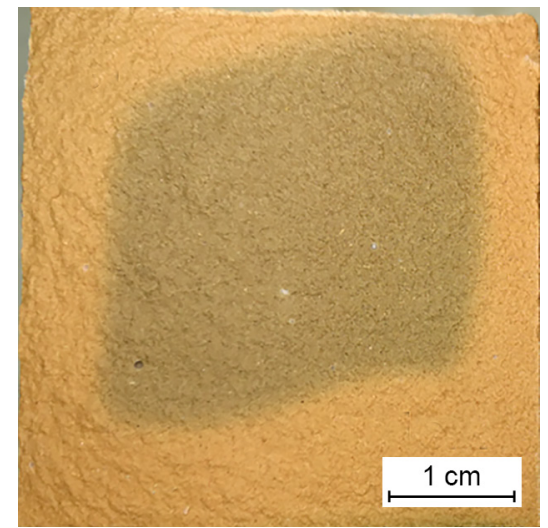

b)

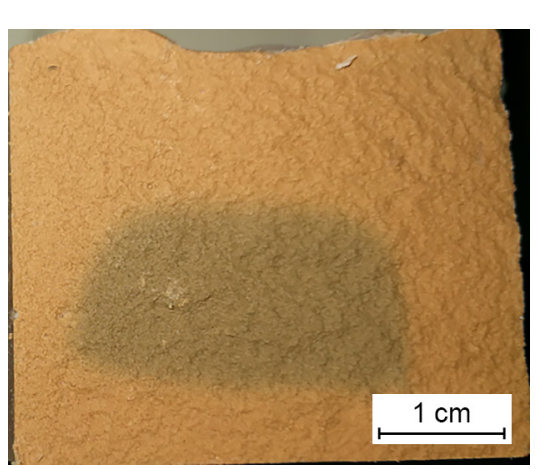

e)

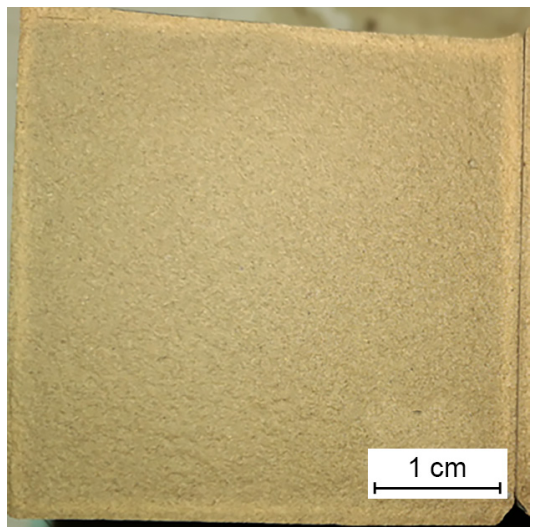

c)

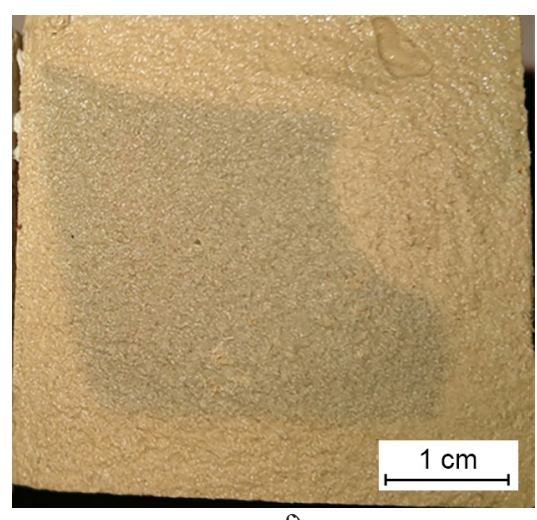

f)

Figure 6. Fracture surface photos of the 28-day SAC1, SAC2 and OPC single slurries (W/Ss of 1.0 and 1.2): a) OPC, 1.0; b) SAC1, 1.0 ; c) SAC2, 1.0; d) OPC, 1.2; e) SAC1, 1.2; f) SAC2, 1.2 . 
have more advantages compared with those of the OPC stone bodies. Figure 7 shows the UCSs ( $3 \mathrm{~d}$ and $28 \mathrm{~d}$ ) of the single slurry stone bodies. The $\mathrm{W} / \mathrm{S}$ ratios of were selected as $0.8,1.0$ and 1.2.

Table 6 presents the FS and UCS of the SAC1, SAC2 and OPC double slurries, the volume ratios were $1: 1,2: 1,3: 1$ and 5:1, and the W/S was selected to be 1.0.

This part can enrich the current research on the FS characteristics of the SAC double slurries, especially considering the combined influence factors such as the cement type, volume ratio, high $\mathrm{W} / \mathrm{S}$, curing time, etc. In Table 6 , the FSs of the double slurry stone bodies (OPC, SAC1 and SAC2) were all lower than those of the single slurries, no matter if the curing age is 3-days or 28-days. To be specific, the 3-day FSs of the SAC1, SAC2 and OPC double slurries (a W/S of 1.0 and a volume ratio of $1: 1-5: 1)$ were $0.21-0.36,0.20-0.41$ and $0.40-1.14 \mathrm{MPa}$, respectively. The 28-day FSs were $0.35-0.61,0.30-1.15$ and $1.27-1.94 \mathrm{MPa}$, respectively. The influence of the mineral constituent or the cement on the FS was significant, and the 3-day and 28-day FSs of the OPC double slurries were higher than those of the SAC. The volume ratios of 1:1 and 5:1 seem to be beneficial to the FSs of the SAC double slurries, the difference between SAC1 and SAC2 is small. The volume ratios of $2: 1-5: 1$ were conducive to the FSs of the OPC double slurries. For the UCSs of the double slurries, the 3-day UCSs of the SAC1, SAC2 and OPC double slurries (a W/S of 1.0 and a volume ratio of $1: 1-5: 1)$ were $0.75-3.03,0.71-1.55$ and $1.30-17.64 \mathrm{MPa}$, respectively. The related 28-day UCSs were $1.70-2.49$, $0.92-3.85$ and $10.85-22.31 \mathrm{MPa}$, respectively. The mineral composition (OPC and SAC) was still the main influencing factor for the UCSs of the double slurries, the 3-day and 28-day UCSs of the SAC double slurries were much lower than those of the OPC, and the difference between SAC1 and SAC2 is small. The effects of the volume ratios of $1: 1-5: 1$ on the UCSs of the SAC double slurries were not obvious. The volume ratio of $2: 1-5: 1$

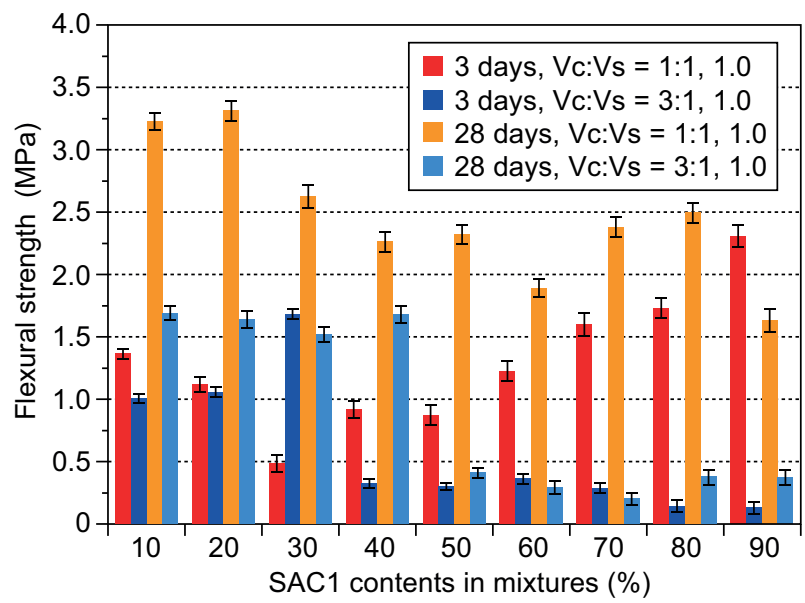

Figure 7. The FS (3d and 28d) of the blended (SAC1+OPC) double slurries. was helpful for the appropriate alkali-activated gelling reaction of the OPC double slurries, and the ratios of 2:1 and 3:1 were more conducive to the UCSs of the OPC double slurries at a W/S of 1.0.

To explore the improvement method for the mechanical strength of the SAC double slurries, blended (SAC1+OPC) double slurries were prepared. Presently, there are few reports about the synergistic effects of the water glass, blended cement, high $\mathrm{W} / \mathrm{S}$, volume ratio and curing time on the FS and UCS of the double slurry grout stone bodies. The FS and UCS values of the key formulations were obtained to fill the corresponding gap in the repair practices. Figure 7 shows the FS of the blended double slurries. SAC1 was chosen as a typical example, the amounts of SAC1 were $10 \%, 20 \%, 30 \%$, $40 \%, 50 \%, 60 \%, 70 \%, 80 \%$ and $90 \%$. The W/S was selected as 1.0, the curing times of 3-days and 28-days were applied, and the volume ratios were chosen as $1: 1$ and $3: 1$.

In Figure 7, the combined effects of the relative amount of the SAC, the volume ratio, the curing time and the high W/S on the FSs were significant, however, the effect of a single factor on the FS variation of the blended double slurries were not relatively obvious. The 3-day and 28-day FSs of the blended double slurries at the volume ratio of $1: 1$ seemed to be higher than those at the volume ratio of $3: 1$, though some randomness existed for the proportion of $30 \% \mathrm{SAC}$. It might be because that the volume ratio of 1:1 might be more appropriate for the alkali excitation of the hydrated minerals of the OPC. When the SAC contents exceeded $30 \%$, the 3-day FSs started to increase for the volume ratio of $1: 1$, while it tended to decrease at the volume ratio of $3: 1$. At the volume ratio of $3: 1$, the 28-day FSs of the blended double slurries tended to obviously decrease when the SAC contents exceeded $40 \%$, and the 28 -day FSs were relatively high when the SAC contents were within $40 \%$. Although the strengths of the OPC double slurries were relatively high, however, their alkalisation white areas at

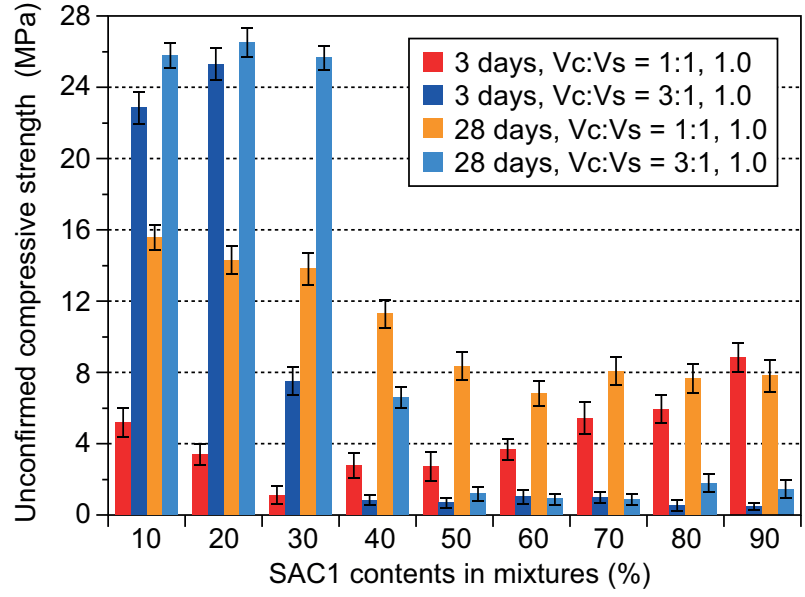

Figure 8. The UCS (3d and 28d) of the blended (SAC1+OPC) double slurries. 


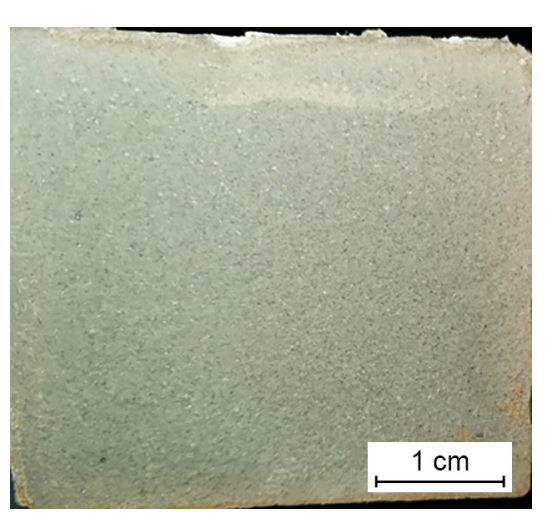

a) $1: 1,10 \% \mathrm{SAC}$

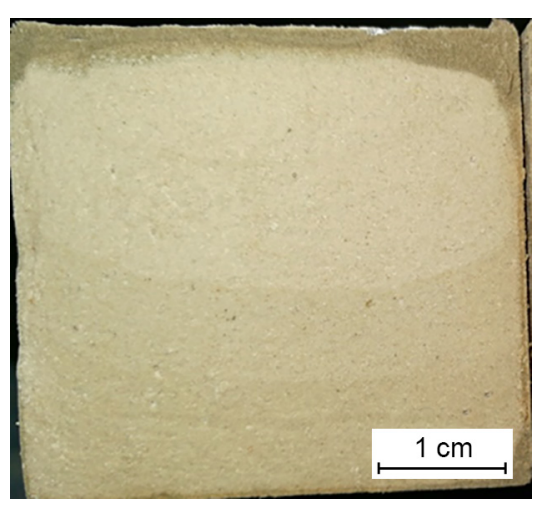

d) $1: 1,40 \% \mathrm{SAC}$

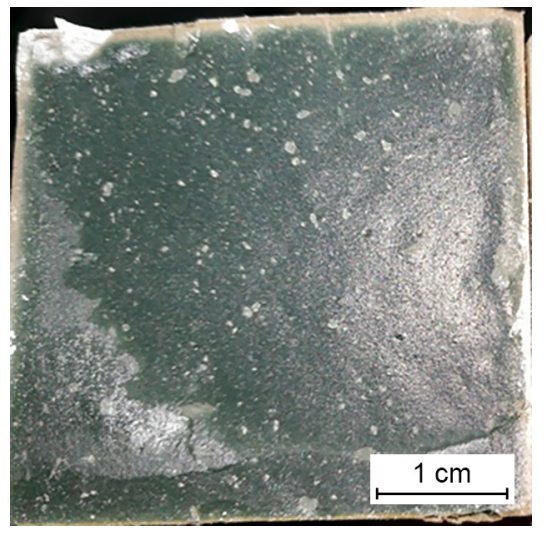

g) $3: 1,10 \% \mathrm{SAC}$

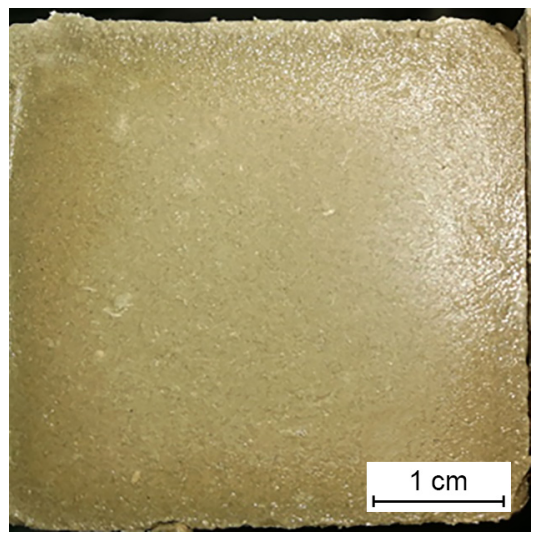

j) $3: 1,40 \% \mathrm{SAC}$

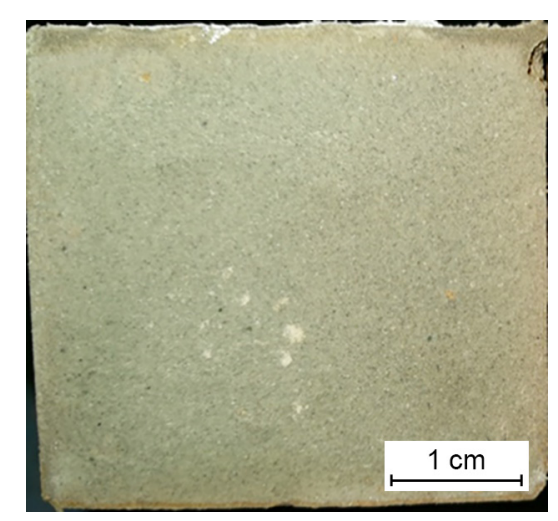

b) $1: 1,20 \% \mathrm{SAC}$

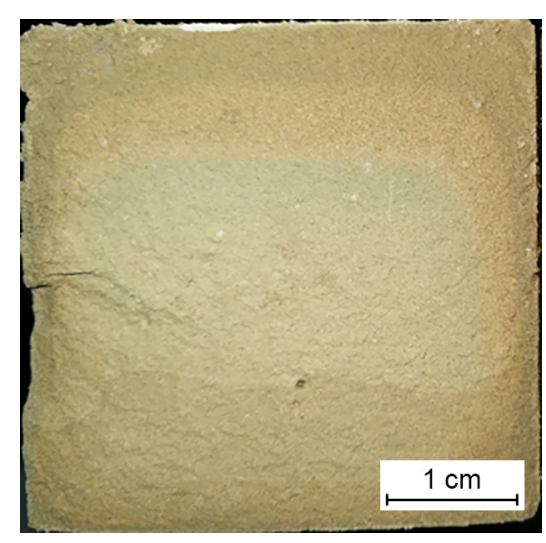

e) $1: 1,60 \% \mathrm{SAC}$

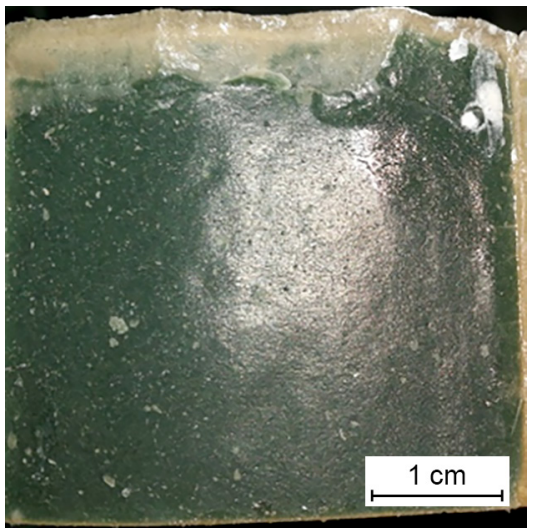

h) $3: 1,20 \% \mathrm{SAC}$

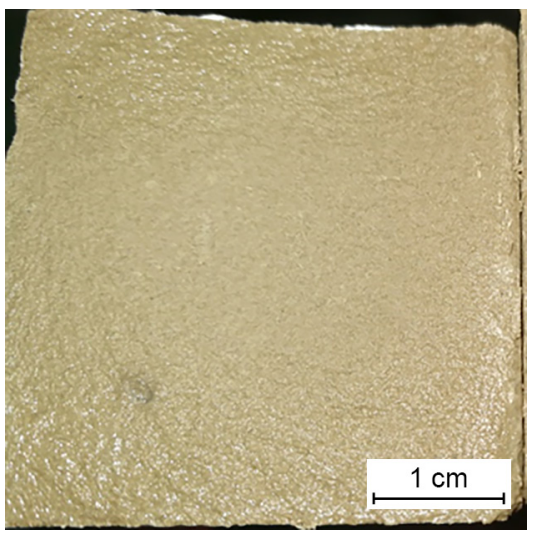

k) $3: 1,60 \% \mathrm{SAC}$

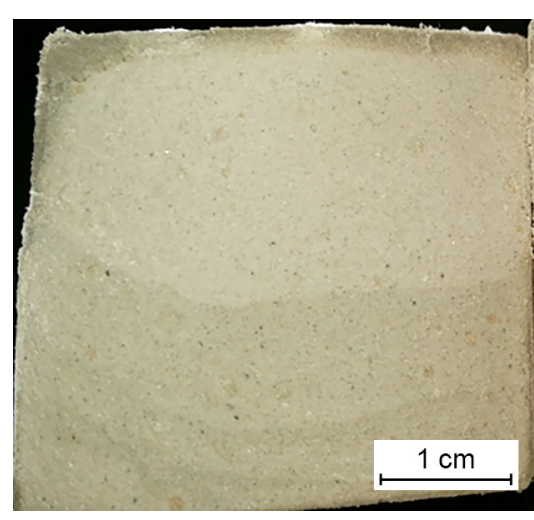

c) $1: 1,30 \% \mathrm{SAC}$

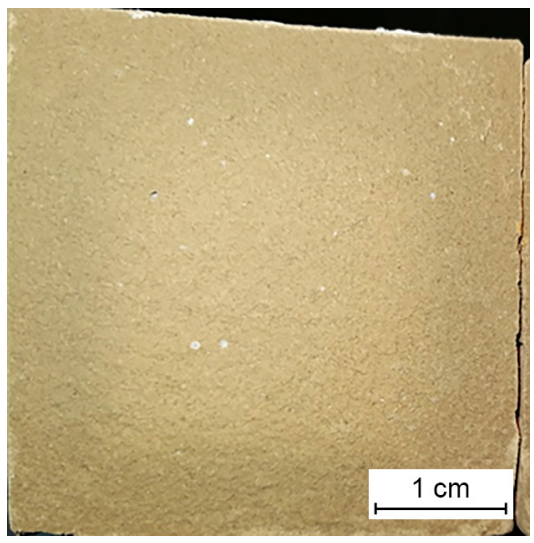

f) $1: 1,90 \% \mathrm{SAC}$

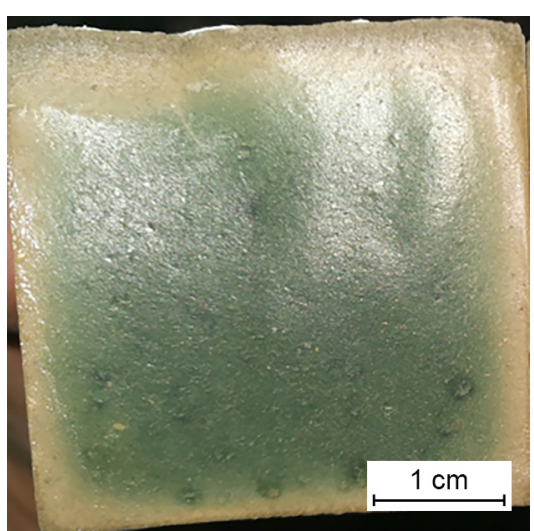

i) $3: 1,30 \% \mathrm{SAC}$

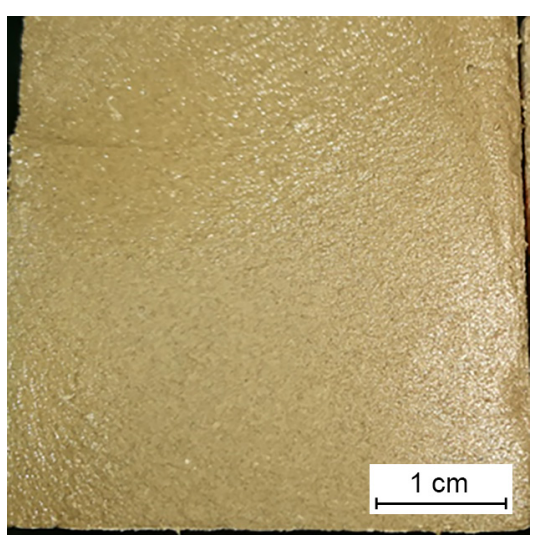

1) $3: 1,90 \% \mathrm{SAC}$

Figure 9. Fracture surface photos of the 28-day blended (SAC+OPC) double slurries (volume ratios of 1:1 and 3:1, W/S of 1.0). 
the volume ratio of $3: 1$ will probably be disadvantageous for the stabilisation in a water-rich environment and with the durability. Figure 8 shows the UCS of the blended double slurries.

In Figure 8, the effects of the relative content of the SAC1 (mineral composition), volume ratio, curing time and high W/S were more significant. At the volume ratio $3: 1$, the UCSs were relatively high when the SAC contents were not over $30 \%$, and the difference between the 3-day and 28-day UCS was maximal when the SAC content was $30-50 \%$. At the volume ratio of $1: 1$, the effects of the curing time on the UCSs were obvious when the SAC content was less than $60 \%$. The UCSs of the blended double slurries were highest when the SAC contents were $0-30 \%$ and the volume ratio was $3: 1$. However, at the volume ratio of $3: 1$, the 28 -day UCSs are not recommended when the SAC contents were over $40 \%$. Combined with the UCSs of the single slurries, the strengths of the blended double slurries were closely related to the mineral composition or content, volume ratio, curing time, etc. The FSs were low when compared with the UCSs especially at the early stages. The combinations of the $10-30 \%$ SAC contents and a volume ratio of $3: 1$ are recommended if the blended double slurries are applied in grouting applications. This part can provide references for the designs and applications of the blended double slurries, especially considering the control and practical influence factors such as the relative content of the mineral or the raw material, volume ratio, curing age, etc. Figure 9 presents the fracture surface photos of the 28-day blended double slurries.

In Figures 9a-f, at the volume ratio of $1: 1$, the colour of the fracture surface changed from bright grey to light brown when the SAC contents ranged from $10 \%$ to $40 \%$, these interval colours were probably helpful for the 28-day FSs and UCSs combined with results of Figure 7 and 8 . The colour typically became brown when

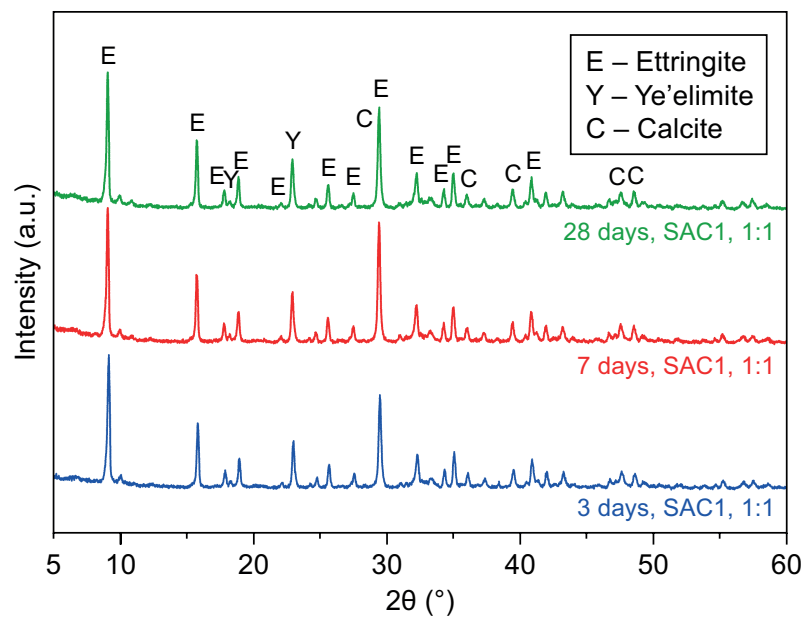

Figure 10. The XRD spectra of the SAC1 single slurries at the different curing days. the SAC contents exceeded $60 \%$, and some obvious efflorescence phenomena existed. In Figures $9 \mathrm{~g}-1$, at the volume ratio of $3: 1$, the colour of the fracture surface changed from dark green-grey to light brown when the SAC contents changed from $10 \%$ to $40 \%$. Combined with the results of Figures 7 and 8, the colours changing from dark green-grey to light green were helpful for the 28-day FS and UCS when the SAC contents were within $30 \%$. The colour typically became brown when the SAC contents exceeded $40 \%$ at the volume ratio of $3: 1$, and the efflorescence phenomena were not obvious. In Figure 9 , the alkalisation of the white areas with different sizes reflected the violent and rapid alkali-activated reactions, especially when the OPC contents were high and the relative proportions of the OPC and sodium silicate were appropriate per volume.

\section{Hydration mineral analysis}

Figure 10 shows the XRD spectra of the SAC1 single slurries. The W/S was selected to be 1.0 , and the curing times were $3 \mathrm{~d}, 7 \mathrm{~d}$ and $28 \mathrm{~d}$. The scanning angle of the XRD test was $5-60^{\circ}$, and the scanning speed was $4-5^{\circ} \cdot \mathrm{min}^{-1}$.

In Figure 10, the main hydration product of the SAC grout was ettringite crystal (AFt), which had generated vigorously at the early age $(3 \mathrm{~d})$. The existing calcite might have been added during the SAC manufacturing process. The aluminium hydroxide was not detected probably because the $\mathrm{AH}_{3}$ gel was amorphous. With the increment of the curing time, the mineral phase $\mathrm{C}_{4} \mathrm{~A}_{3} \overline{\mathrm{S}}$ was greatly consumed and $\mathrm{AFt}$ accumulates continuously. The presence of the $\mathrm{AH}_{3}$ gel or $\mathrm{C}-\mathrm{S}-\mathrm{H}$ gel might lead to the hump at the bottom of the XRD spectra. The diffraction intensity difference between the different curing ages were relatively small and the 28-day AFt peak strength did not obviously increase. The reasons might be that the $\mathrm{Al}$ element in the AFt structure could be easily replaced by other elements such as Fe, $\mathrm{Si}$, etc., AFt was also likely to be solidly fused with these elements $[42,43]$. Meanwhile, the W/S of 1.0 was relatively high and the bleeding of the SAC was relatively low.

\section{Pore size distribution analysis}

The pore size distributions of the SAC and OPC hardened grouts were studied. The measurement results are exhibited in Figure 11. The initial W/S was 1.0 and the volume of the $y$-axis represented the intrusion amount of the mercury.

In Figure 11, the cumulative volume of the 28-day SAC grout stone body was slightly higher than that of the OPC, and the pore size distribution of the OPC has some advantages over that of the OPC. Pores with smaller sizes $(<10 \mathrm{~nm})$ are generally classified into the gel pores [44], the amounts of gel pores of the SAC hardened grout seemed to be higher. This might be because that the 


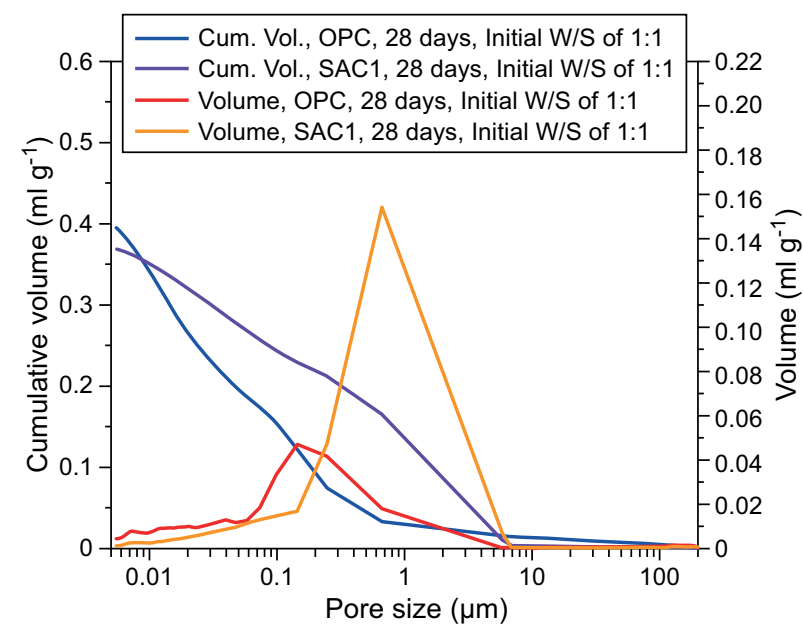

Figure 11. The pore size distributions of the 28-day SAC and OPC single slurries at a $\mathrm{W} / \mathrm{S}$ of 1.0 .

effective W/S of the SAC is higher than that of OPC when the initial $\mathrm{W} / \mathrm{S}$ is the same. For example, at the initial $\mathrm{W} / \mathrm{S}$ of 1.0 , the effective $\mathrm{W} / \mathrm{S}$ of SAC1 was 0.83 , while that of OPC was 0.73 . The difference in the effective $\mathrm{W} / \mathrm{S}$ between the SAC and OPC might be the real reason for the distinctions in the pore size distribution. A large number of big pores were present in the hardened OPC or SAC grout, which might be due to the high initial W/S, bleeding, sediment, etc., The newly produced hydration products are advised to fill large pores whose diameters exceed $100 \mathrm{~nm}$, thus, these pores will be transformed into smaller ones.

\section{Erosion resistance coefficient}

Figure 12 shows the erosion resistance coefficients of the SAC1, SAC2 and OPC single slurry stone bodies. The erosion resistance coefficients were calculated as the average ratios of the FSs in the erosion solutions

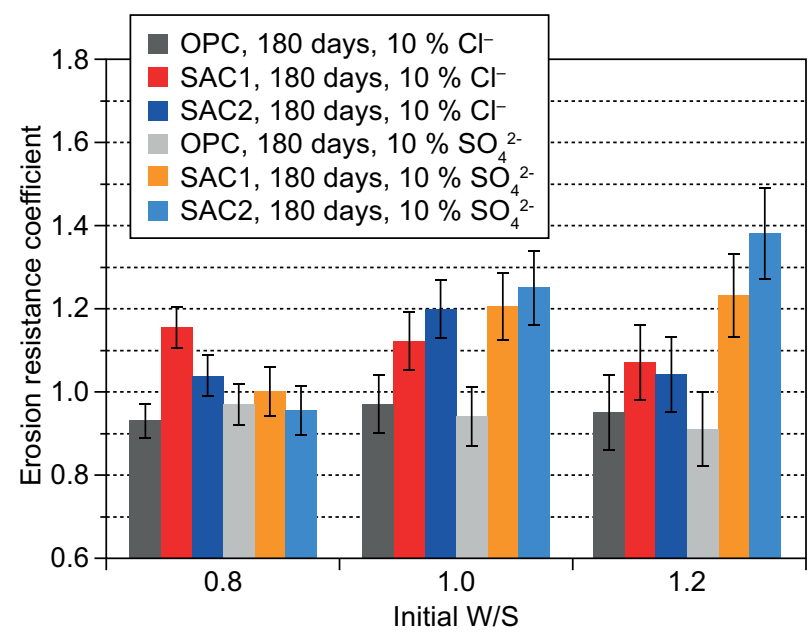

Figure 12. The 180-day erosion resistance coefficients of the SAC1, SAC2 and OPC single slurry stone bodies. and those in the water. The erosion concentration of the sulfate ion and chloride ion was chosen as $10 \%$, and the curing time was 180 days.

In Figure 12, the sulfate erosion resistance coefficients of the SAC1 or SAC2 stone bodies were much higher than 1.0 at the initial $\mathrm{W} / \mathrm{S}$ of 1.0 and 1.2. The difference between the sulfate coefficient of SAC1 and SAC2 was small, and attention should be paid to the increase in the randomness with an increase in the W/S. This might be because that the main mineral $\mathrm{C}_{4} \mathrm{~A}_{3} \overline{\mathrm{S}}$ of the SAC hydrated to form high amounts of AFt, and the AFt can be stable in a sulfate environment for a long time. The amounts of AFt in the SACG stone bodies might increase significantly because of their relatively high porosity especially at the high W/S of $1.0-1.2$. Although the chloride erosion resistance coefficients of the SAC1 or SAC2 stone bodies were not very high, they exceeded 1.0 in general. There was no obvious chloride coefficient difference for the SAC1 and SAC2 stone bodies at the W/S of $0.8-1.2$. In comparison, the sulfate or chloride erosion resistance coefficients of the OPC stone bodies were relatively low and close to 1.0. The existed deviations in Figure 13 might be because that the FSs were relatively low compared with the UCSs, the flexural fracture was easily caused due to the obvious brittleness, and the related improvement seemed to be more sensitive. Meanwhile, the higher bleeding rate at the higher W/Ss might contribute to these deviations. The erosion resistance coefficients could provide references for the corrosion-resistance evaluation of slurry stone bodies, it is suggested to combine the erosion resistance coefficients with the specific mechanical performance.

\section{Microstructure}

The 180-day single slurry stone bodies (SAC1, SAC2 and OPC) under different environments were prepared, and their microstructures were measured through SEM methods. The SEM results are shown in Figures 13a-i. The W/S of the single slurry was selected as 1.0 , and the environments were water, a $10 \%$ sodium chloride solution and a $10 \%$ sodium sulfate solution, respectively.

In Figures 13a-c, for the OPC single slurry stone bodies, obvious cracks and cavities appeared in the three envi-ronments. Compared with the microstructures of the OPC stone bodies in water, the cracks were more obvious in the chloride solution, the degrees of gelatinisation interconnection among the gels decreased and the porosity increased especially in the erosion solutions with a high concentration (10\%) of sulfate ions. In Figures $13 \mathrm{~d}-\mathrm{f}$, for the SAC single slurry stone bodies, there were no obvious cracks, though cavities existed with different degrees. In Figure 13d, thick and thin needle shaped ettringite crystals and a small amount of calcium hydroxide existed, meanwhile, the microstructure was not so dense. In Figure 13e, large cavities and loose 
microstructures still existed for the SAC1 stone bodies in the chloride solution. In Figure 13f, well developed columnar ettringite and amorphous gels mainly existed, and the compactness of microstructure seemed to be improved. In conclusion, for the SAC slurry stone bodies, the concentration of the ettringite increased, the morphology of the ettringite tended to become thick needle-like or columnar in shape in the erosion solutions with a high concentration sulfate ions, and the porosity of SAC1 and SAC2 were not high.

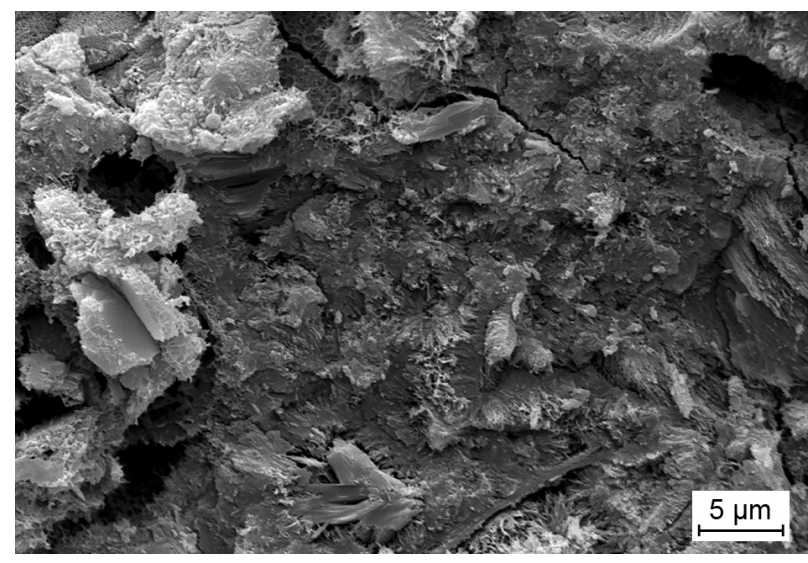

a)

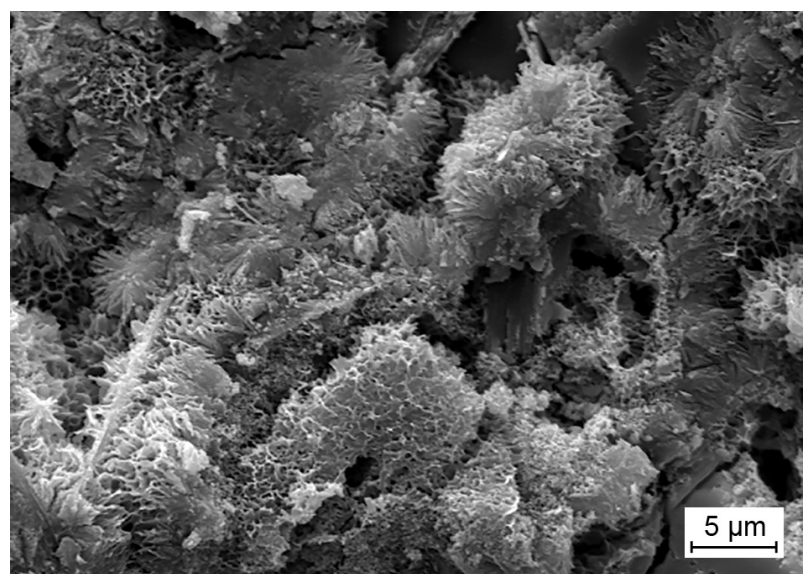

c)

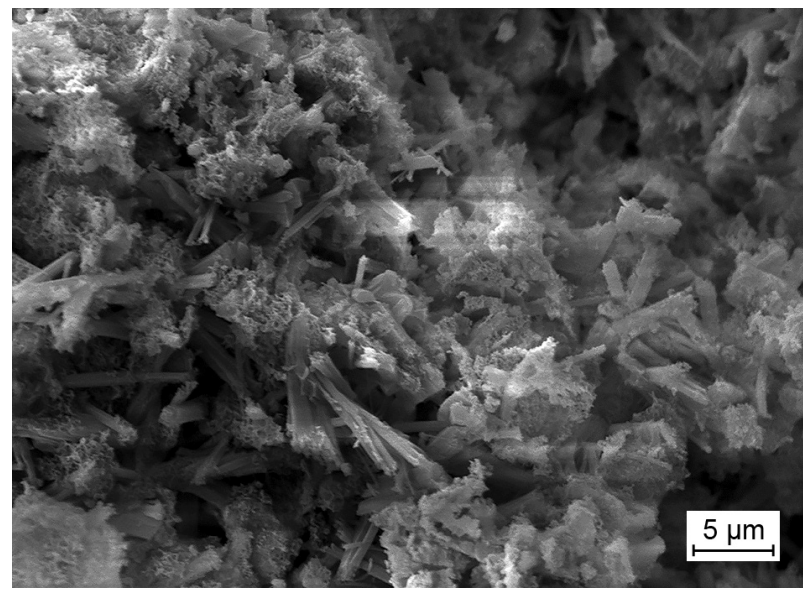

e)

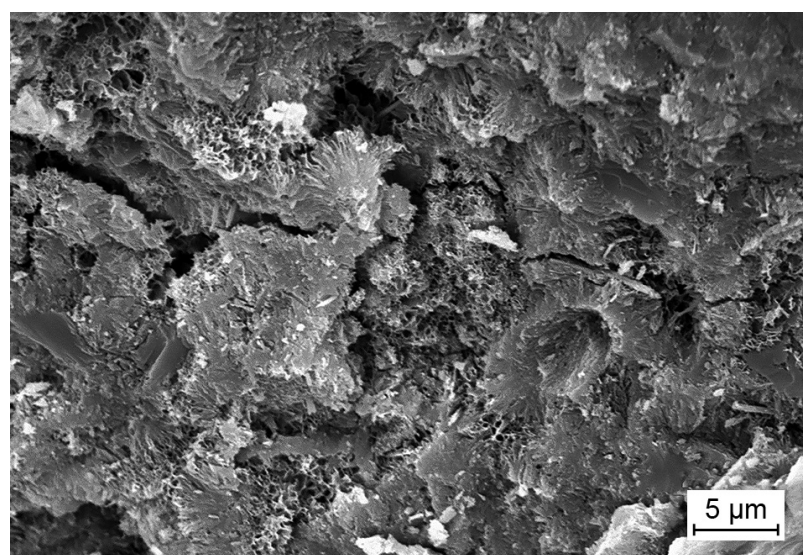

b)

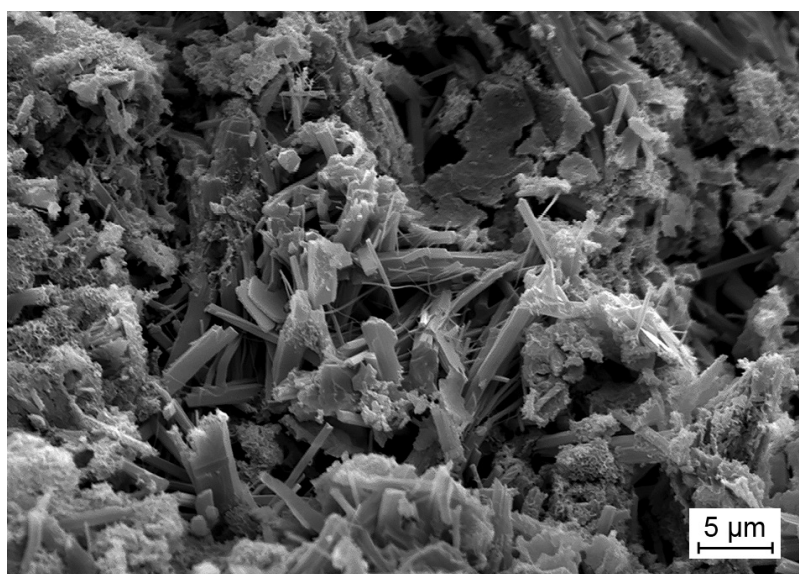

d)

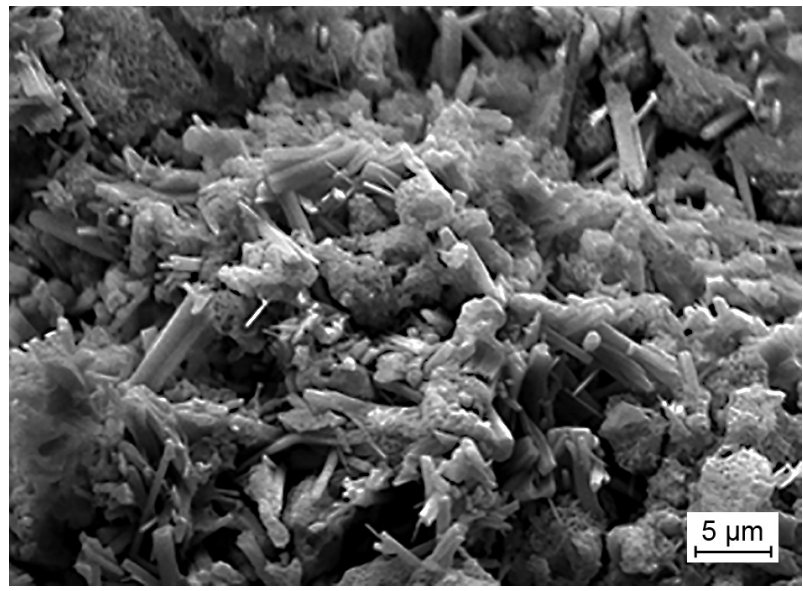

f)

Figure 13. SEM photos of the OPC and SAC single slurry stone bodies (initial W/S of 1.0) under different conditions: a) OPC, 180-day, water; b) OPC, 180-day, $10 \%$ concentration of chloride solution; c) OPC, 180-day, $10 \%$ concentration of sulfate solution; d) SAC1, 180-day, water; e) SAC1, 180-day, $10 \%$ concentration of chloride solution; f) SAC1, 180-day, $10 \%$ concentration of sulfate solution. 


\section{CONCLUSIONS}

- Compared with the effect of the mineral composition, the W/S was the control influencing factor especially when the W/S was over 1.0. The AWA and SP should be used together to enhance both the stability and flowability. The mineral composition of the SAC is potentially beneficial to obtain high effective W/Ss and short initial/final setting times.

- As for the flowability losing time of the double slurries, the mineral composition and volume ratio were the main influencing factors, and it decreased with an increase in the volume ratio $(1: 1-5: 1)$ and a decrease in the W/S. The flowability losing times of the OPC double slurries were smaller (less than $60 \mathrm{~s}$ ). The fresh-state property differences between the SAC slurries were small.

- Although the early FSs of the SAC single slurries were higher than those of the OPC, the FS developments of the SAC were smaller than those of the OPC at a W/S of $0.8-1.2$. The FSs of the double slurries were all lower than those of the single slurries. The FS differences between SAC1 and SAC2 were small. The 28-day FSs were relatively high when the SAC1 contents were within $40 \%$.

- The mineral composition was still the main influencing factor for the UCS s of the double slurries, the UCSs of the SAC double slurries were much lower than those of the OPC, and the difference between SAC1 and SAC2 was small. The volume ratios of $2: 1$ and $3: 1$ were conducive to the UCSs of the OPC double slurries. The UCSs of the blended double slurries were highest when the SAC contents were $10 \%-30 \%$ and the volume ratio was $3: 1$.

- The sodium silicate single slurry had negative effects on the mechanical strength of the SACG. The blended SACG double slurries can help increase the mechanical strength, especially when the SAC contents were within $30 \%$. The effective W/S should be considered to evaluate the pore size distribution characteristic and the mechanical strength.

- The sulfate erosion resistance coefficients of the SAC1 or SAC2 grouts were much higher than 1.0. The concentration of ettringite increased, the ettringite tended to increase and become thick needle-like or columnar in shape in the high concentration sulfate ions. The cracks, cavities and loose microstructure of the OPC might have adverse effects on the long-term stability in erosion environments.

\section{Acknowledgement}

This study was financially supported by the National Natural Science Foundation of China (grant numbers 51909140; 51778632) andhe China Postdoctoral Science Foundation (2018M642658).

\section{REFERENCES}

1. Tani M.E. (2012): Grouting rock fractures with cement grout. Rock Mechanics and Rock Engineering, 45(4), 547-561. doi: 10.1007/s00603-012-0235-0

2. Sha F., Lin C.J., Li Z.F., Liu R.T. (2019): Reinforcement simulation of water-rich and broken rock with Portland cement-based grout. Construction and Building Materials, 221, 292-300. doi: 10.1016/j.conbuildmat.2019.06.094

3. Sha F., Li S.C., Lin C.J., Liu R.T., Zhang Q.S., Yang L., Li Z.F. (2019): Research on penetration grouting diffusion experiment and reinforcement mechanism for sandy soil porous media. Rock and Soil Mechanics, 40(11), 4259-4269. doi: 10.16285/j.rsm.2019.0133. (In Chinese)

4. Lee J.S., Bang C.S., Mok Y.J., Johc S.H. (2000): Numerical and experimental analysis of penetration grouting in jointed rock masses. International Journal of Rock Mechanics and Mining Sciences, 37(7), 1027-1037. doi: 10.1016/S13651609(00)00040-X

5. Sha F., Li S.C., Liu R.T., Li Z.F., Zhang Q.S. (2018): Experimental study on performance of cement-based grouts admixed with fly ash, bentonite, superplasticizer and sodium silicate. Construction and Building Materials, 161, 282-291. doi: 10.1016/j.conbuildmat.2017.11.034

6. Perret S., Palardy D., Ballivy G. (2000): Rheological behavior and setting time of microfine cement-based grouts. ACI Materials Journal, 97, 472-478.

7. Mirza J., Saleh K., Langevin M.A., Mirza S., Bhuttad M.A.R., Tahir M.M. (2013): Properties of microfine cement grouts at $4{ }^{\circ} \mathrm{C}, 10{ }^{\circ} \mathrm{C}$ and $20^{\circ} \mathrm{C}$. Construction and Building Materials, 47, 1145-1153. doi: 10.1016/j.conbuildmat.2013. 05.026

8. Glasser F.P., Zhang L. (2001): High-performance cement matrices based on calcium sulfoaluminate-belite compositions. Cement and Concrete Research, 31(12), 1881-1886. doi: 10.1016/S0008-8846(01)00649-4

9. Cheng X., Chang J., Lu L.C., Liu F.T., Teng B. (2000): Study of Ba-bearing calcium sulphoaluminate minerals and cement. Cement and Concrete Research, 30(1), 77-81. doi: 10.1016/S0008-8846(99)00204-5

10. Gastaldini A.L.G., Isaia G.C., Saciloto A.P., Missau F., Hoppe T.F. (2010): Influence of curing time on the chloride penetration resistance of concrete containing rice husk ash: a technical and economical feasibility study. Cement and Concrete Composites, 32(10), 783-793. doi: 10.1016/j. cemconcomp.2010.08.001

11. Li G.X., Zhang J.J., Song Z.P., Shi C., Zhang A. (2018): Improvement of workability and early strength of calcium sulphoaluminate cement at various temperature by chemical admixtures. Construction and Building Materials, 160, 427-439. doi: 10.1016/j.conbuildmat.2017.11.076

12. Sherman N., Beretka J., Santoro L., Valenti G.L. (1995): Long-term behaviour of hydraulic binders based on calcium sulfoaluminate and calcium sulfosilicate. Cement and Concrete Research, 25(1), 113-126. doi: 10.1016/0008-8846 (94)00119-J

13. Beretka J., Vito B.D., Santoro L., Sherman N., Valenti G.L. (1993): Hydraulic behaviour of calcium sulfoaluminatebased cements derived from industrial process wastes. Cement and Concrete Research, 23(5), 1205-1214. doi: 10.1016/0008-8846(93)90181-8

14. Winnefeld F., Lothenbach B. (2010): Hydration of calcium sulfoaluminate cements-experimental findings and thermo- 
dynamic modelling, Cement and Concrete Research, 40(8), 1239-1247. doi: 10.1016/j.cemconres.2009.08.014

15. Kasselouri V., Tsakiridis P., Malami C., Georgali B., Alexandridou C. (1995): A study on the hydration products of a nonexpansive sulfoaluminate cement. Cement and Concrete Research, 25(8), 1726-1736. doi: 10.1016/00088846(95)00168-9

16. Chaignat L.P., Winnefeld F., Lothenbach B., JörgMüllerb C. (2012): Beneficial use of limestone filler with calcium sulphoaluminate cement. Construction and Building Materials, 26(1), 619-627. doi: 10.1016/j.conbuildmat.2011. 06.065

17. Sha F., Li S.C., Liu R.T., Zhang Q.S., Li Z.F. (2019): Performance of typical cement suspension-sodium silicate double slurry grout. Construction and Building Materials, 200, 408-419. doi: 10.1016/j.conbuildmat.2018.12.119

18. Güllü H. (2014): A factorial experimental approach for effective dosage rate of stabilizer: An application for finegrained soil treated with bottom ash. Soils and Foundations, 54(3), 462-477. doi: 10.1016/j.sandf.2014.04.017

19. Sha F., Li S..C, Liu R.T., Li Z.F., Zhang Q.S. (2018): Effects of fineness on viscoelasticity of microfine cementbased grouts with fly ash, silica fume and superplasticiser. Advances in Cement Research, 30(10), 469-481. doi: 10.1680/jadcr.17.00054

20. Mirza J., Mirza M.S., Roy V., Saleha K. (2012): Basic rheological and mechanical properties of high-volume fly ash grouts. Construction and Building Materials, 16(6), 353-363. doi: 10.1016/S0950-0618(02)00026-0

21. Li S.C., Sha F., Liu R.T. Li W., Li Z.F., Wang G.C. (2017): Properties of cement-based grouts with high amounts of ground granulated blast-furnace slag and fly ash. Journal of Materials in Civil Engineering, 29(11), 04017219. doi: 10.1061/(ASCE)MT.1943-5533.0002083

22. Saleh S., Yunus N.Z.M., Ahmad K., Ali N. (2019): Improving the strength of weak soil using polyurethane grouts: A review. Construction and Building Materials, 16(6), 738-752. doi: 10.1016/j.conbuildmat.2019.01.048

23. ASTM, Standard Specification for Portland Cement, ASTM C150/C150M-19a, West Conshohocken, PA, 2019.

24. Eriksson M, Friedrich M, Vorschulze C. (2003): Variations in the rheology and penetrability 533 of cement-based grouts-an experimental study. Cement and Concrete Research, 34(7), 1111-1119.

25. Li S.C., Sha F., Liu R.T., Zhang Q.S., Li Z.F. (2017): Investigation on fundamental properties of microfine cement and cement-slag grouts. Construction and Building Materials, 153, 965-974. doi: 10.1016/j.conbuildmat.2017. 05.188

26. ISO 13320-1, Particle size analysis - Laser diffraction methods - Part 1 General principles, International Organization for Standardization, ISO13320-1, Geneva, Switzerland, 1999.

27. ASTM, Standard Test Method for Slump of HydraulicCement Concrete, ASTM C143/ C143M-15a, West Conshohocken, PA, 2015.

28. Li S.C., Sha F., Liu R.T., Li Z.F., Zhang Q.S. (2017): Investigation on viscous behavior and strength of microfinecement-based grout mixed with microfine fly ash (MFA) and superplasticizer (SP). Advances in Cement Research, 29(5), 206-215. doi: 10.1680/jadcr.16.00118

29. ASTM, Standard Test Method for Flow of grout for preplaced-aggregate concrete (flow cone method), ASTM C939-10, West Conshohocken, PA, 2010.

30. Ozawa K., Sakata N., Okamura H. (1995): Evaluation of self compactibility of fresh concrete using the funnel test. Proc. of JSCE Concrete Library International. 25, 61-70.

31. ASTM, Standard Test Method for Expansion and Bleeding of Freshly Mixed Grouts for Preplaced-Aggregate Concrete in the Laboratory, ASTM C940-16, West Conshohocken, PA, 2016.

32. Saleh K., Mirza J., Ballivy G. (1993): Selection criteria for Portland and microfine cement-based injection grouts. In: Proceedings international conference on grouting in rock and concrete, Salzburg. Rotterdam: Balkema Publ., 97-105.

33. Bras A., Gião R., Lúcio V., Chastre C. (2013): Development of an injectable grout for concrete repair and strengthening. Cement and Concrete Composites, 37, 185-195. doi: 10.1016/j.cemconcomp.2012.10.006

34. ASTM, Standard Test Methods for Time of Setting of Hydraulic Cement by Vicat Needle, ASTM C191-13, West Conshohocken, PA, 2013.

35. ASTM, Standard Test Method for Flexural Strength of Concrete (Using Simple Beam with Third-Point Loading), ASTM C78/C78M-16, West Conshohocken, PA, 2016.

36. GB/T 17671-1999, Method of testing cements-Determination of strength, Chinese National Quality and Technical Supervision \& Chinese Ministry of Construction, BJ, 1999.

37. ASTM, Standard Test Method for Compressive Strength of Grouts for Preplaced-Aggregate Concrete in the Laboratory, ASTM C942-15, West Conshohocken, PA, 2015.

38. ASTM, Standard Test Method for Compressive Strength of Cylindrical Concrete Specimens, ASTM C39/C39M-16, West Conshohocken, PA, 2016.

39. GB/T 749-2008, Test method for determining capability of resisting sulfate corrode of cement, Chinese National Quality and Technical Supervision \& Chinese Ministry of Construction, BJ, 2008.

40. ASTM, Standard Test Method for Flexural Strength and Modulus of Elasticity of Chemical-Resistant Mortars, Grouts, Monolithic Surfacings, and Polymer Concretes, ASTM C580-18, West Conshohocken, PA, 2018.

41. Rosquoe F, Alexis A, Khelidj A, Phelipot A. (2003): Experimental study of cement grout: Rheological behavior and sedimentation. Cement and Concrete Research, 33(5), 713-722. doi: 10.1016/S0008-8846(02)01036-0

42. Li D.D. (1984): Infrared spectroscopic study of sulfoaluminate cement. Journal of Chinese ceramic society, 12(1), 119-125. (in Chinese)

43. He Z., Yang H.M., Liu M.Y. (2014): Hydration mechanism of sulphoaluminate cement. Journal of Wuhan University of Technology, 29(1), 70-74. doi: 10.1007/s11595-014-0869-8

44. Cook R., Hover K. (1999): Mercury porosimetry of hardened cement pastes. Cement and Concrete Research, 29(6), 933-943. doi: 10.1016/S0008-8846(99)00083-6 